\title{
Earthquake Response and Pushover Analysis of Piloti Buildings Supported by SRC Columns
}

\author{
Mi-jin Park ${ }^{1}$, Tae-jun Yeom ${ }^{2}$, Jae-seong Ju², Kang-geun Park ${ }^{3, *}$ \\ ${ }^{1}$ Department of Architecture and Urban Design, Incheon National University, Republic of Korea \\ ${ }^{2}$ Department of Architecture, Incheon National University, Republic of Korea \\ ${ }^{3}$ Department of Architectural Engineering, CKP Wind Engineering Institute, Republic of Korea
}

Received February 16, 2020; Revised March 19, 2020; Accepted March 28, 2020

Copyright $\bigcirc 2020$ by authors, all rights reserved. Authors agree that this article remains permanently open access under the terms of the Creative Commons Attribution License 4.0 International License

\begin{abstract}
The existing piloti buildings with supported reinforced concrete columns were very vulnerable to earthquake ground motions. Since piloti buildings are composed of the wall structure system in the upper part of the building and a relatively flexible beam-column system in the lower part of the building, piloti buildings are structurally vulnerable in the event of large transverse vibrations and cause collapses during an earthquake. This study aims to analyze the dynamic response behavior and capacity estimation of piloti buildings with a steel reinforced concrete column system on the first floor. To investigate the earthquake response of piloti buildings, the time history and pushover increment analyses are used to analyze the collapse pattern and capacity estimation of piloti buildings. The present piloti buildings constructed by reinforced concrete experienced most of the deformation on the first floor when an earthquake occurred, as shown in the yielding fracture of the columns on the first floor. From the results of this study, the piloti buildings supported by SRC reinforced concrete columns have enough strength and safety for a five-story building, but also have the required strength and safety for a ten-story building.
\end{abstract}

Keywords Piloti Buildings, Steel Box Column, Time History Analysis, Pushover Analysis, Earthquake Response Analysis

\section{Introduction}

Although the design standards for piloti buildings were recently strengthened and studies of earthquake performance estimation were conducted actively, one must study the dynamic response characteristics of the structures to various seismic ground waves during the structural design of piloti buildings. This stems from serve damages occurring in the columns of low-rise buildings considered seismic design and in other structural members. In the event of a strong earthquake, the lower frames were developed with the structural system of a soft mechanism, and most of the damages occurred in the columns and shear walls on the first floor of a building. Damage to the lower frames of the building is critical in the collapse of the entire building, and large compressions and tensile forces can be generated in the lower structural frames by the lateral force of an earthquake. Since the wall system in the upper part of the buildings is rigid in structure and the lower part of the buildings is supported as a flexible beam-column system, piloti buildings are structurally vulnerable in the event of large transverse vibrations by earthquakes and are representative examples of building collapses due to an earthquake. Figure 1 shows the collapse of buildings by a large earthquake. The damages of buildings are columns, beams, and wall failures, the overturning of structures, the fall off of exterior cladding, the fall off interior finish, the tsunami, and the radiation damage of nuclear power plants, landslides, and fires by gas pipe failures. Figure 2 shows the case of piloti buildings causing the collapse of the columns by a small earthquake.

This study analyzed the seismic behavior of piloti buildings using the earthquake response analysis and pushover analysis. Because the stiffness of the upper structure of piloti buildings is greater than that of the lower structure, the upper structure provides the rigid behavior and the lower frames produce a large deformation by an earthquake ground motion. Since the piloti buildings generate an excessive axial force in the columns, it is difficult to secure the required ductility of the structural system. Besides the excessive strength factor, the structural requirements are needed to limit the axial force ratio of the column. In piloti buildings, large shear forces occurred on the columns in the lower part of the building. It was reported that the piloti buildings with reinforced concrete 
columns caused most of the destruction in the columns on the first floor and that the earthquake resistance capacity was reduced after reaching the maximum resistance at a deformation angle of $1 / 100$ for the height of the building[1-5]. The earthquake response and earthquake resistance capacity can be estimated using the time history analysis and the pushover analysis [6,7]. The pushover analysis uses a nonlinear technique to estimate seismic structure performance and it simulates the phenomenon by applying loads until the weak link in the structure is found. This process continues until a yield pattern of the overall structures is determined $[8,9]$.

The existing piloti buildings with supported reinforced concrete (SRC) columns were vulnerable to earthquake ground motions. This study evaluated the dynamic response and seismic performance using the time history analysis and the pushover analysis for the El Centro earthquake and the Mexico earthquake in the piloti buildings supported by SRC columns to ensure structural stability against earthquakes. The results of the time history analysis were estimated to analyze the dynamic response (displacement response, acceleration response) according to the seismic waves. The pushover analysis analyzed the resistance capability of the structural members of piloti buildings to earthquakes.

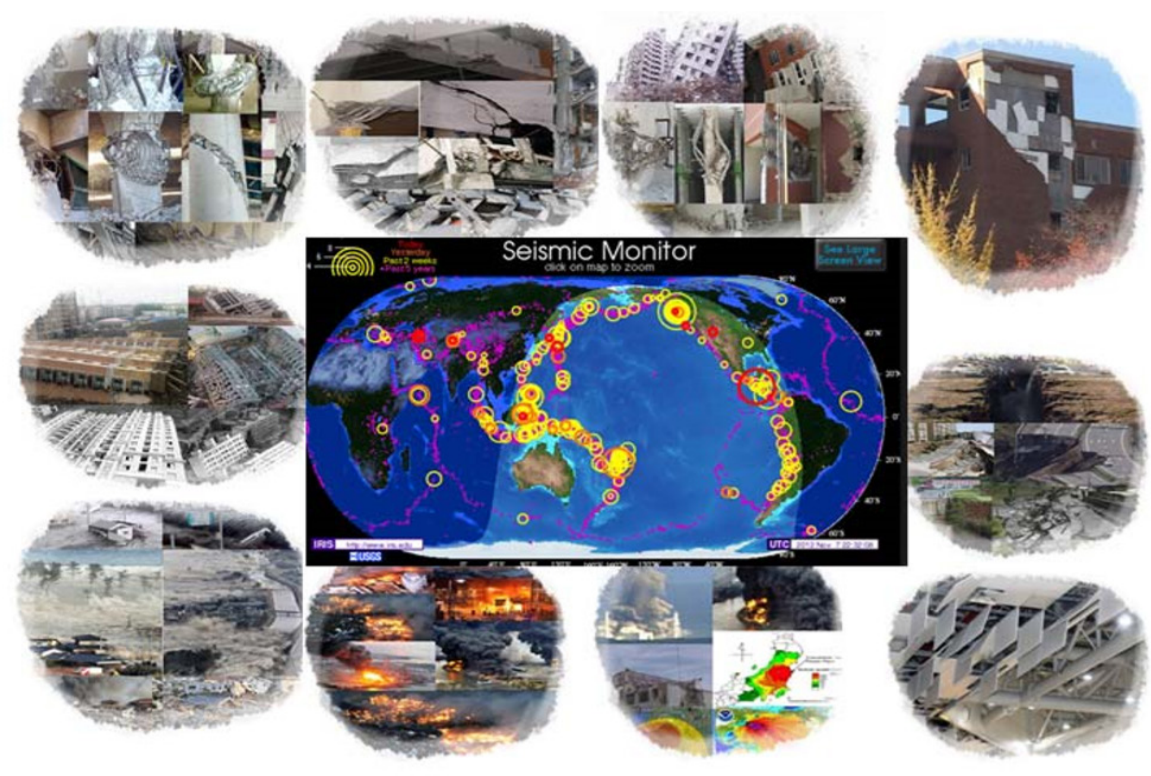

Figure 1. Damage pattern of buildings by huge earthquakes

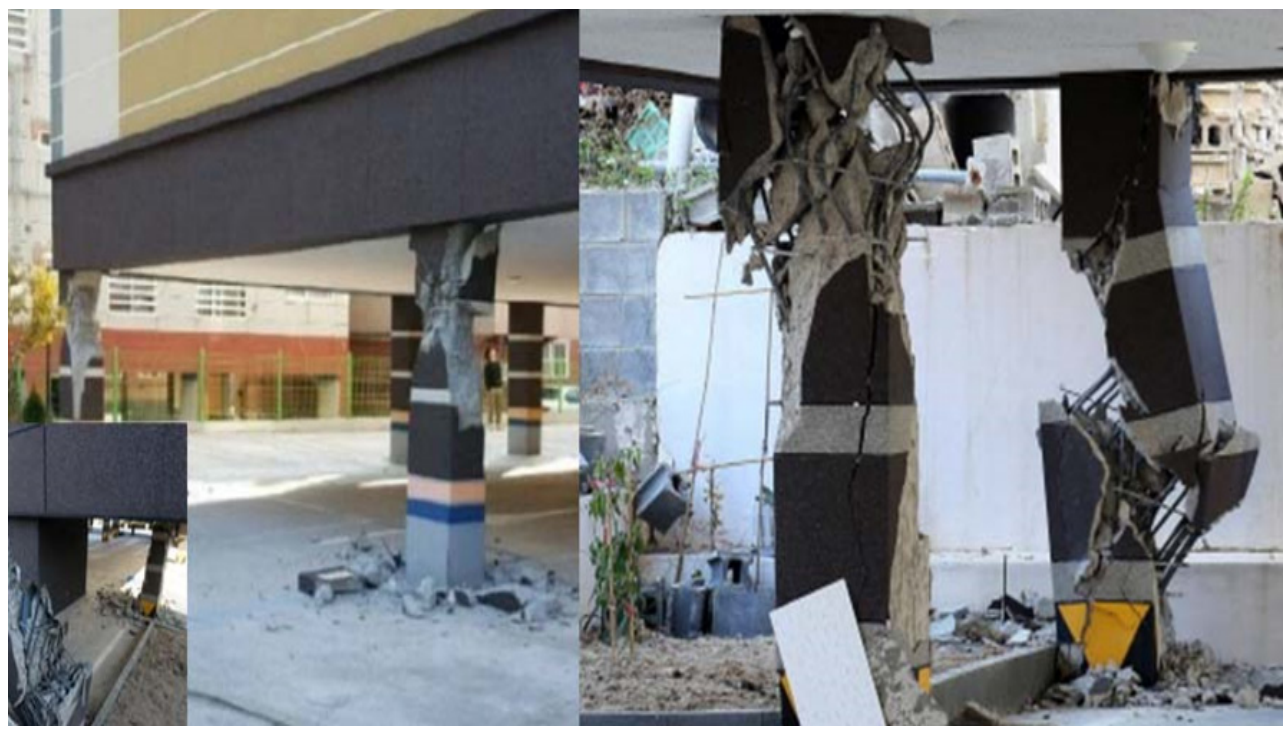

Figure 2. Column collapses of a piloti building 


\section{Earthquake Response and Pushover Analysis of a Five-story Building}

\subsection{Earthquake Response of a Five-story Building}

Seismic response and performance evaluation using the time history analysis are conducted to assess structural stability against earthquake ground motions for a five-story piloti building. The self-weight of the slab is $0.5 \mathrm{kN} / \mathrm{m}^{2}$ and the applied live load is $3.0 \mathrm{kN} / \mathrm{m}^{2}$. The seismic standard is applied in seismic zone I, ground type (Stiff soil) Sd, important factor 1.2, and the response modification factor is 3. The seismic analysis standard was applied to the El Centro seismic wave $(\mathrm{PGA}=0.3569 \mathrm{~g})$ and the scale down seismic wave $(\mathrm{PGA}=0.3569 \times 0.6=0.214 \mathrm{~g})$ for seismic response and seismic performance evaluation. Figure 3 is a numerical model and deformations by earthquake ground motion. The primary period of the building is 0.2769 , and the second period is 0.2703 , as shown in Table 1 . In the first period, displacement by mass in the $x$-direction is dominant, and in the secondary mode, the displacement by mass in the $y$-direction is dominant.

Figures 4 and 5 are displacement response curves of the time history analysis for the El Centro earthquake, and Figures 6 and 7 are acceleration response curves. For the maximum ground acceleration of $0.214 \mathrm{~g}$, a displacement of $-8.6 \mathrm{~mm} \sim 7.6 \mathrm{~mm}$ and acceleration of $-412 \mathrm{gal} \sim 429$ gal occurred in the $x$-direction. In the $y$-direction, displacements of $-8.6 \mathrm{~mm} \sim 7.6 \mathrm{~mm}$ and acceleration of $-441 \mathrm{gal} \sim 491 \mathrm{gal}$ were observed. In the history analysis of the maximum ground acceleration $0.3569 \mathrm{~g}$, a displacement of $-24 \mathrm{~mm} \sim 21 \mathrm{~mm}$ and acceleration of $-1,146$ gal $\sim 1,194$ gal occurred in the $x$-direction, and a displacement of $-24 \mathrm{~mm} \sim 21 \mathrm{~mm}$ and acceleration of $-1,224 \mathrm{gal} \sim 1,364 \mathrm{gal}$ in the $y$-direction are shown in Figures 8 to 11 . For the Mexico earthquake (maximum ground acceleration $=0.1714 \mathrm{~g}$ ), displacements in the $x$-direction are $-5.1 \mathrm{~mm}$ to $5.2 \mathrm{~mm}$ and accelerations are -236 gal to 255 gal. Displacements in the $y$-direction of $-4.9 \mathrm{~mm}$ to $4.5 \mathrm{~mm}$ and accelerations of -218 gal to 241 gal were generated in Figures 12 to 15.

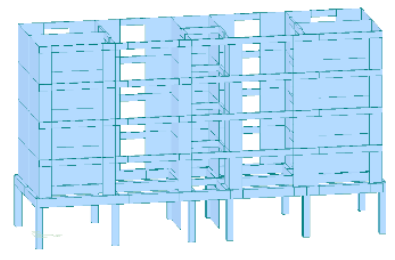

(a) model

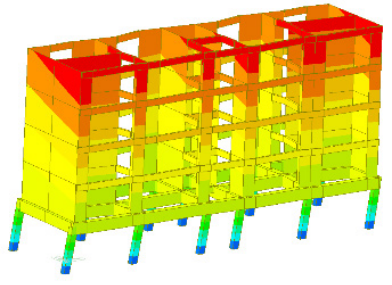

(b) mode 1: $0.038 \mathrm{~m}$

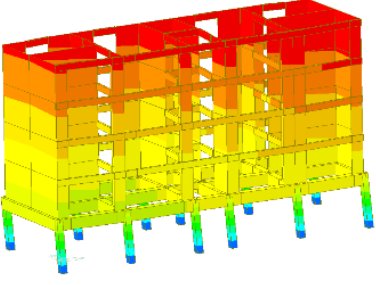

(c) mode 2: $0.052 \mathrm{~m}$

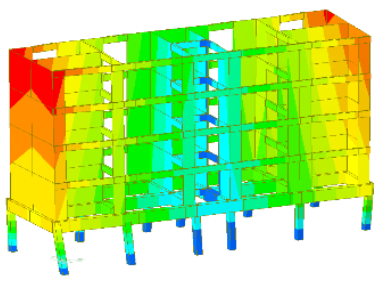

(d) mode 3: $0.049 \mathrm{~m}$

Figure 3. Vibration mode shape $(B \times D=8 \mathrm{~m} \times 27 \mathrm{~m}$, SRC column: Box $-500 \times 500 \times 30$, SS275)

Table 1. Results for eigenvalue analysis

\begin{tabular}{|c|c|c|c|}
\hline \multirow{2}{*}{ Mode } & \multicolumn{3}{|c|}{ Eigenvalue analysis } \\
\cline { 2 - 4 } & Frequency (rad/sec) & Frequency (cycle/sec) & Period (sec) \\
\hline 1 & 22.6889 & 3.6111 & 0.2769 \\
\hline 2 & 23.2422 & 3.6991 & 0.2703 \\
\hline 3 & 26.5980 & 4.2332 & 0.2362 \\
\hline
\end{tabular}

Table 2. Nodal participation masses

\begin{tabular}{|c|c|c|c|c|c|c|}
\hline \multirow{2}{*}{ Mode } & \multicolumn{6}{|c|}{ Nodal participation masses (\%) } \\
\hline & $\mathbf{X}$ & $\mathbf{Y}$ & $\mathbf{Z}$ & $\mathbf{R x}$ & Ry & $\mathbf{R z}$ \\
\hline 1 & 96.5417 & 0.0244 & 0.0 & 0.0 & 0.0 & 1.1723 \\
\hline 2 & 0.0156 & 97.8020 & 0.0 & 0.0 & 0.0 & 0.1095 \\
\hline 3 & 1.3344 & 0.0894 & 0.0 & 0.0 & 0.0 & 97.6547 \\
\hline
\end{tabular}




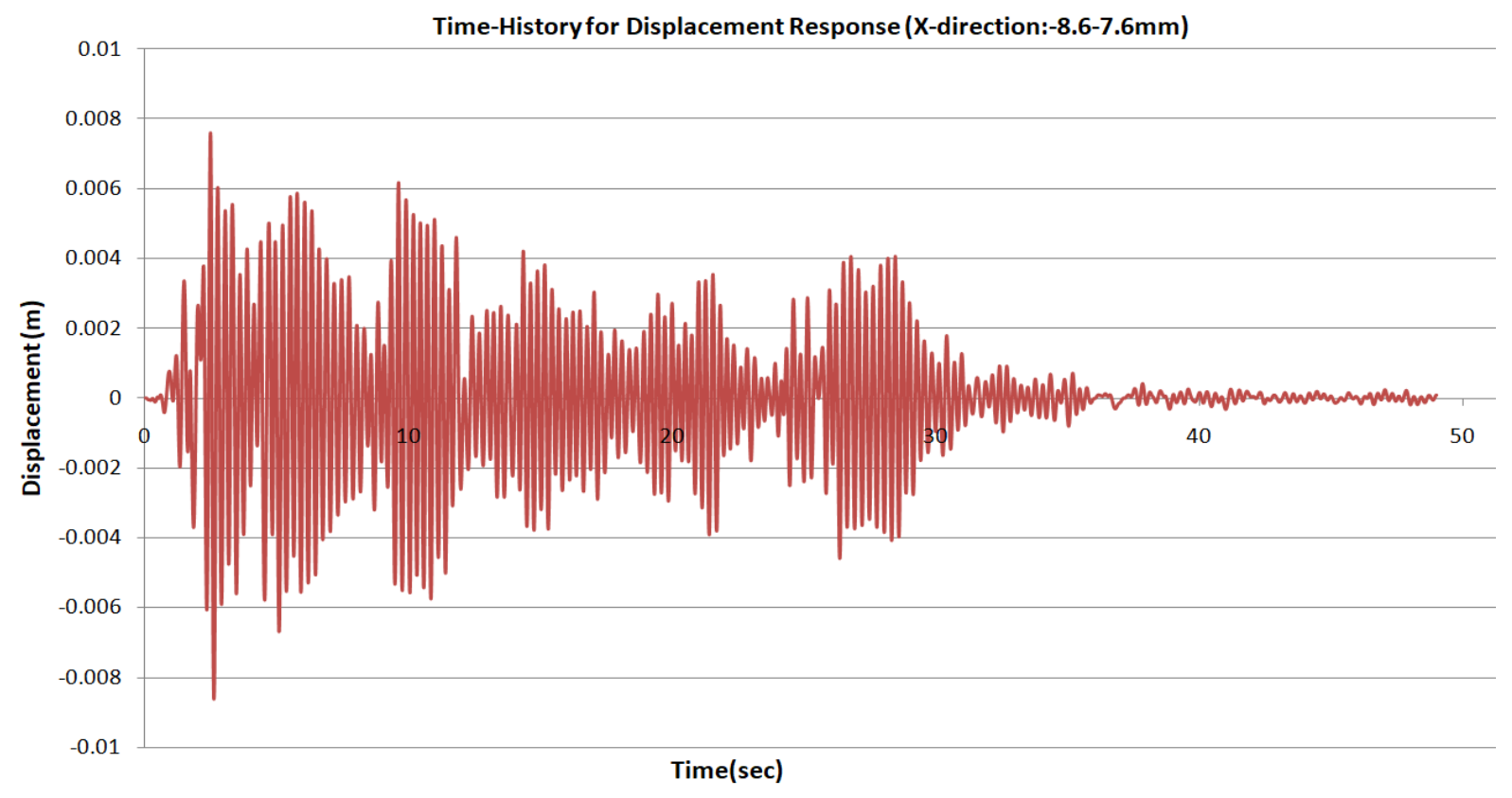

Figure 4. Displacement response for $x$-direction (El Centro: $\mathrm{PGA}=0.3569 \times 0.6=0.214 \mathrm{~g}$ )

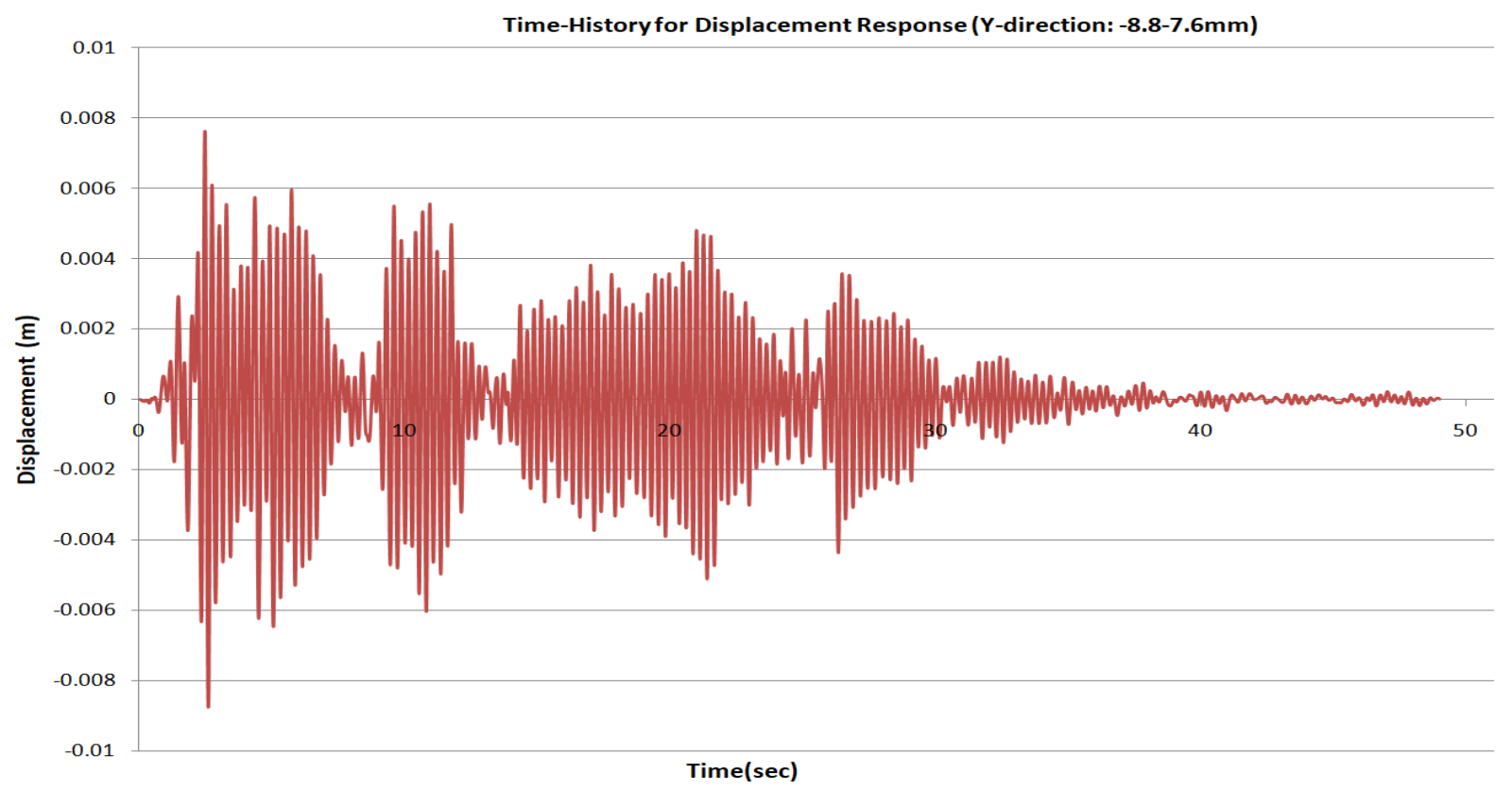

Figure 5. Displacement response for $y$-direction (El Centro: $\mathrm{PGA}=0.3569 \times 0.6=0.214 \mathrm{~g}$ ) 


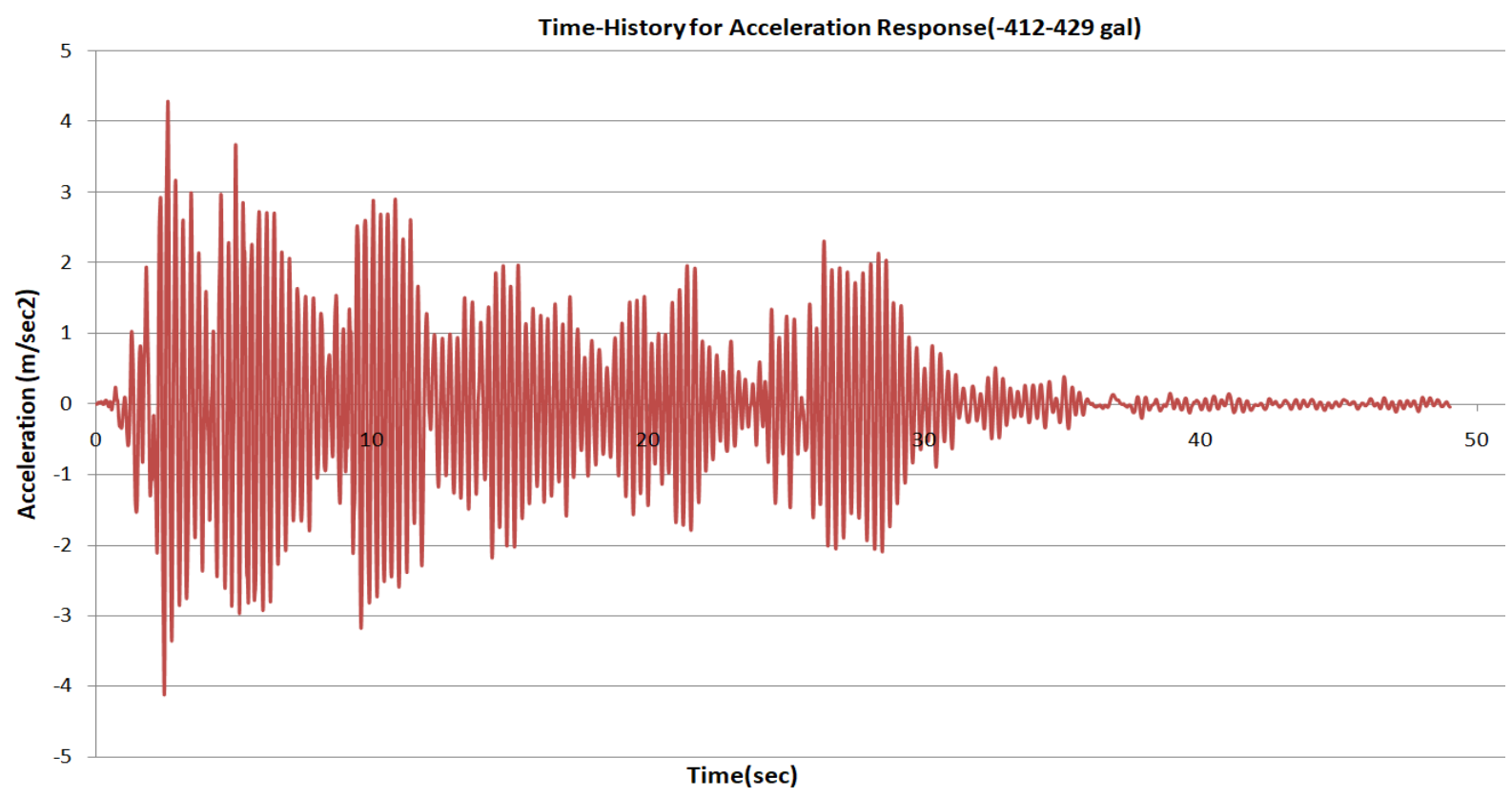

Figure 6. Acceleration response for $x$-direction (El Centro: $\mathrm{PGA}=0.3569 \times 0.6=0.214 \mathrm{~g}$ )

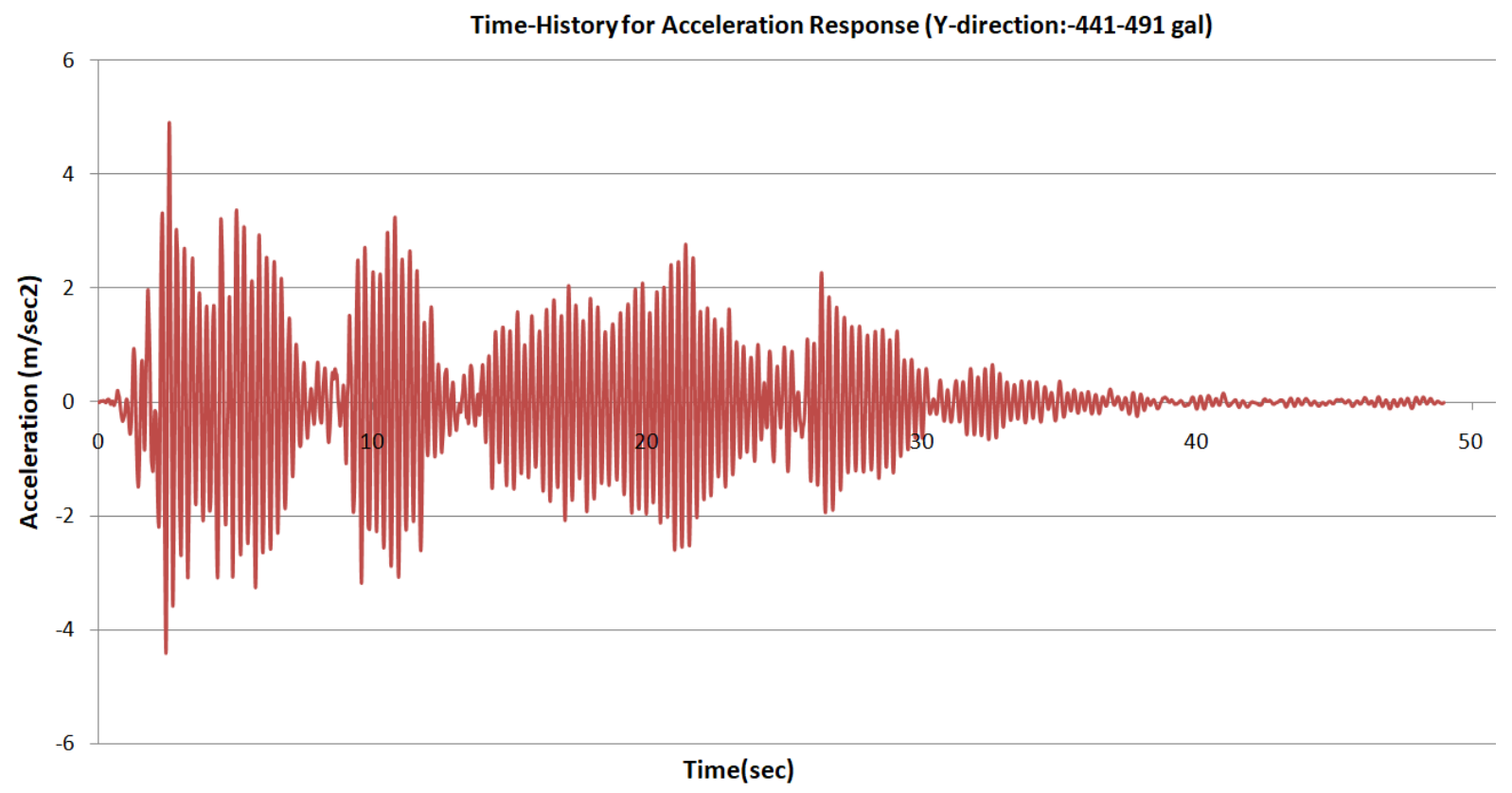

Figure 7. Acceleration response for $y$-direction (El Centro: $\mathrm{PGA}=0.3569 \times 0.6=0.214 \mathrm{~g}$ ) 


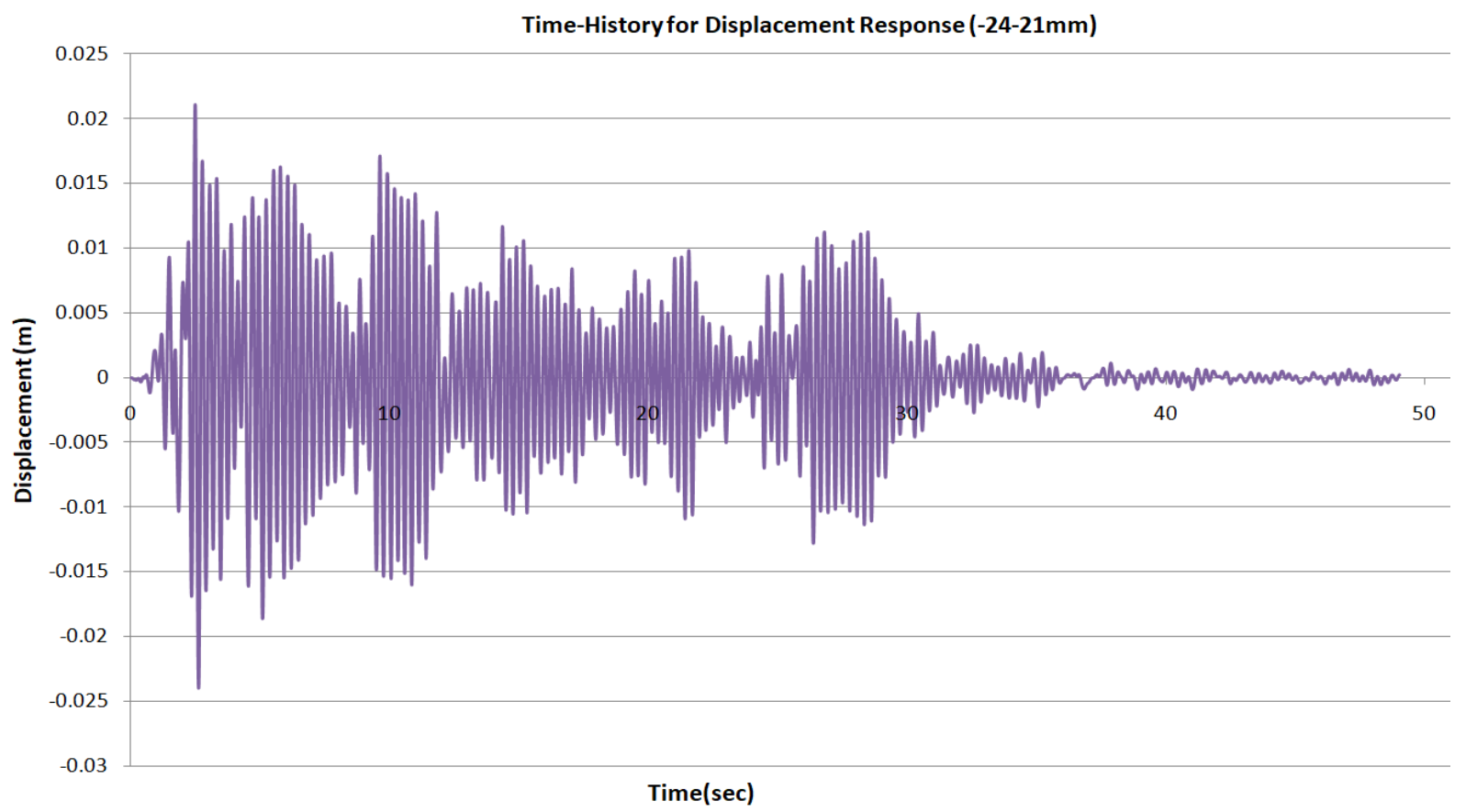

Figure 8. Displacement response for $x$-direction (El Centro: PGA $=0.3569 \mathrm{~g}$ )

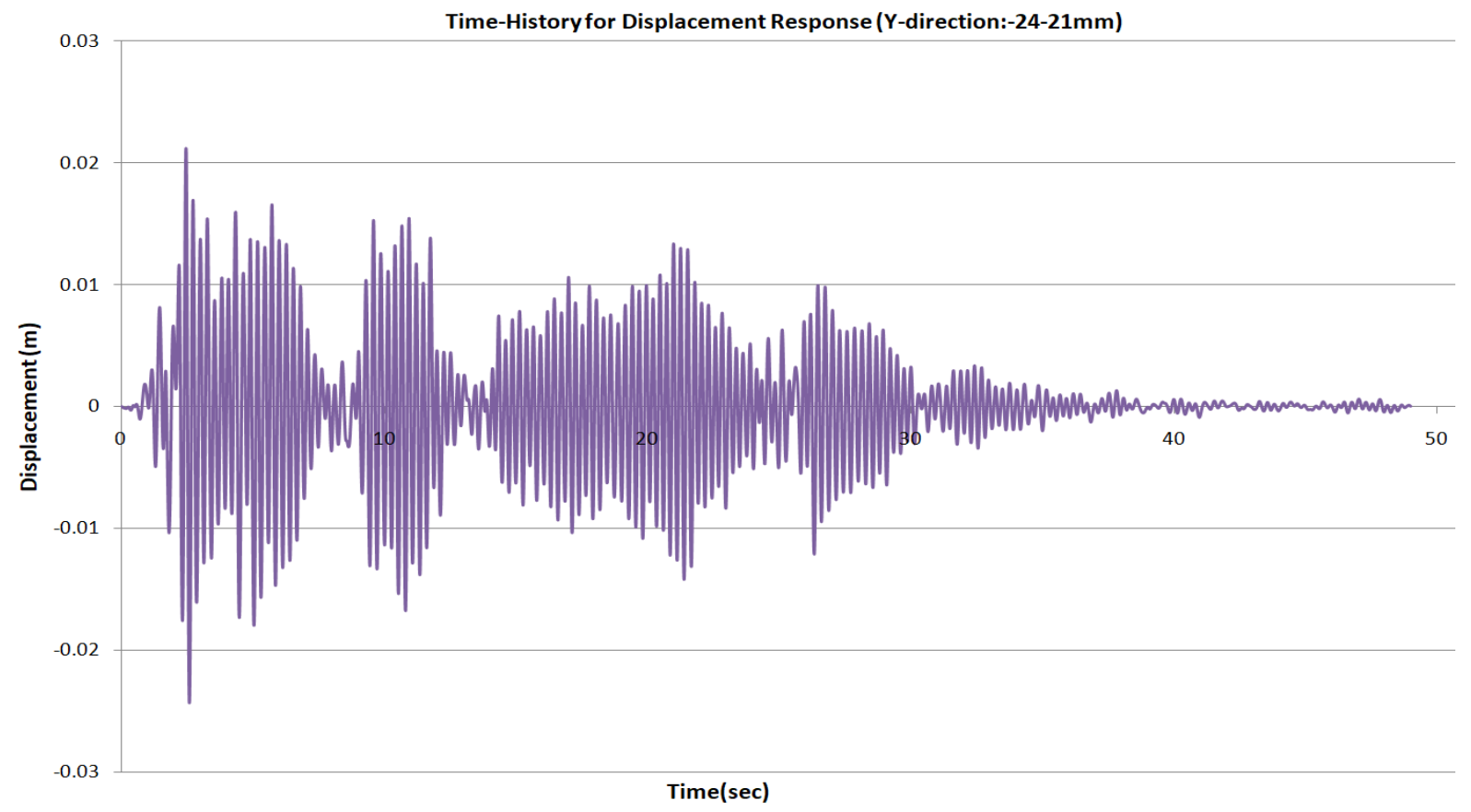

Figure 9. Displacement response for $y$-direction (El Centro: $\mathrm{PGA}=0.3569 \mathrm{~g}$ ) 


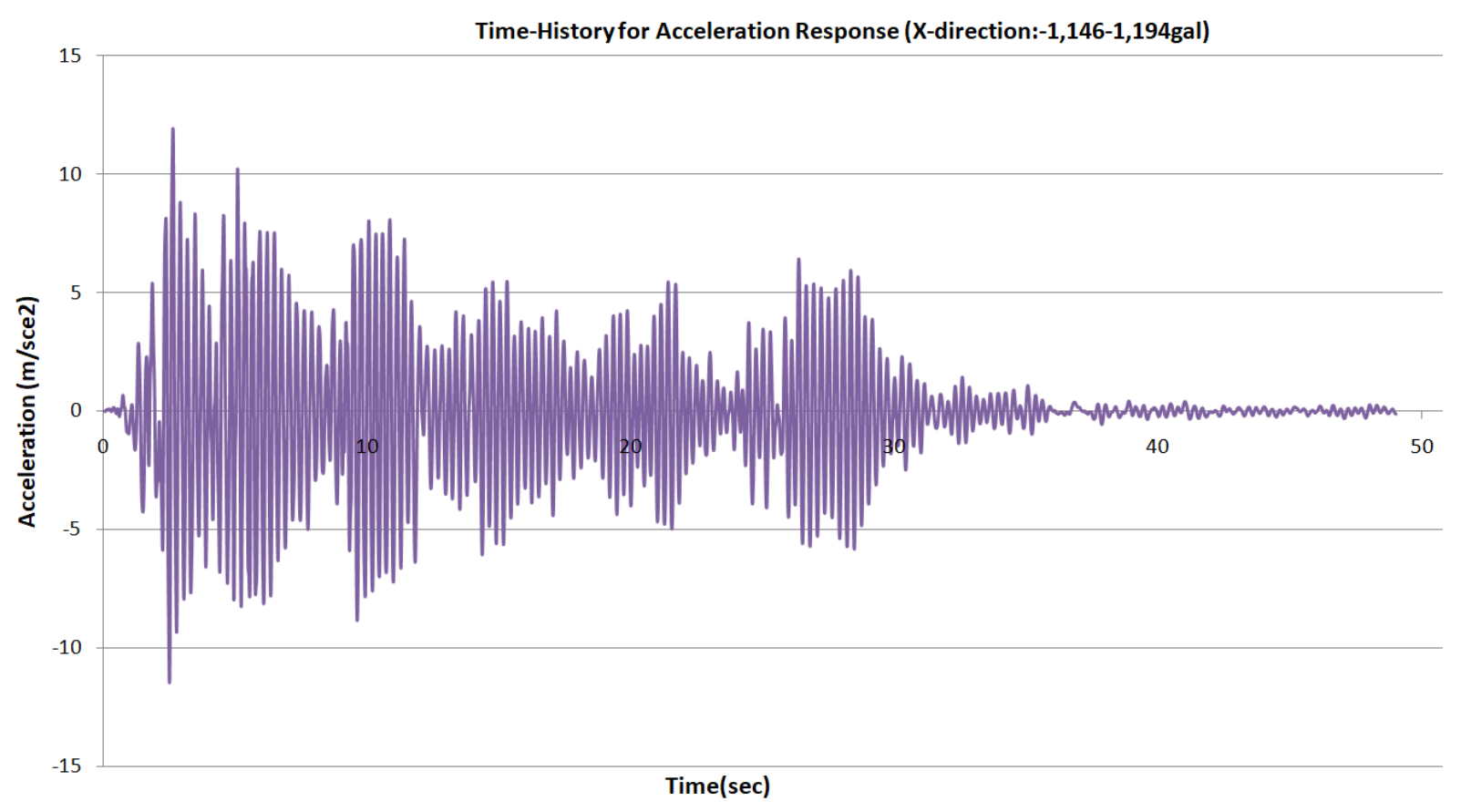

Figure 10. Acceleration response for $x$-direction (El Centro: PGA $=0.3569 \mathrm{~g}$ )

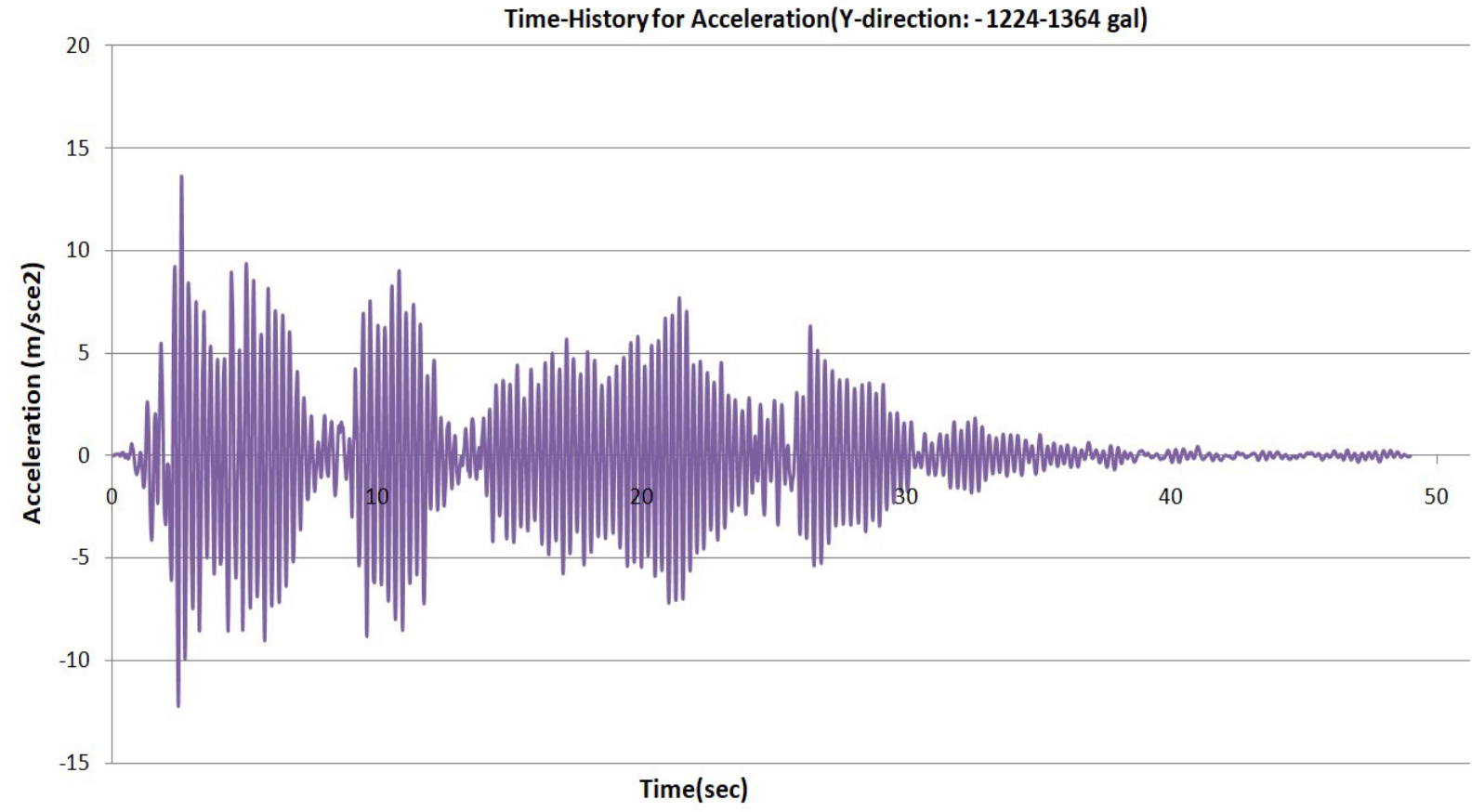

Figure 11. Acceleration response for $y$-direction $(\mathrm{El}$ Centro: $\mathrm{PGA}=0.3569 \mathrm{~g})$ 


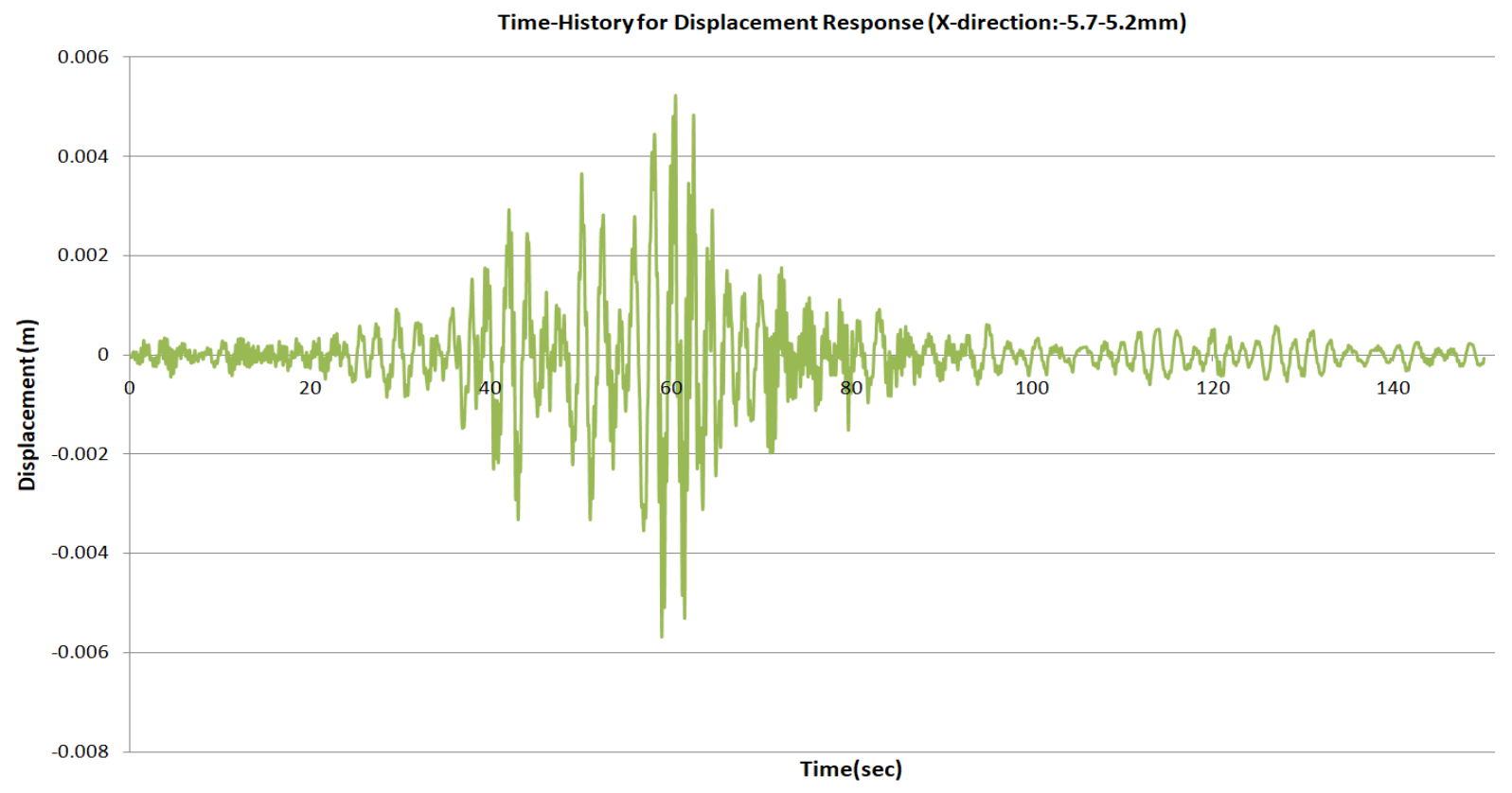

Figure 12. Displacement response for $x$-direction (Mexico: $\mathrm{PGA}=0.1714 \mathrm{~g}$ )

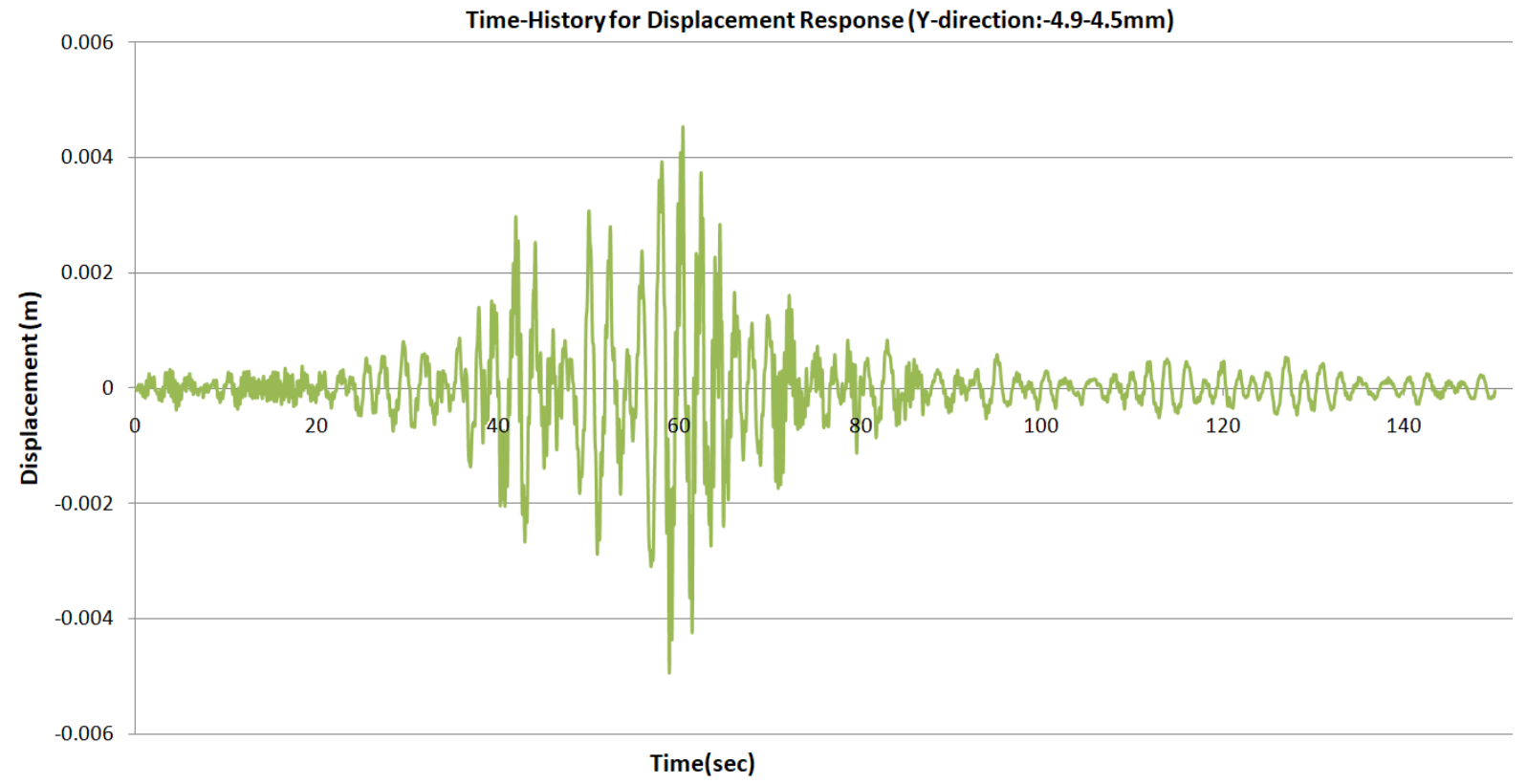

Figure 13. Displacement response for $y$-direction (Mexico: $\mathrm{PGA}=0.1714 \mathrm{~g}$ ) 


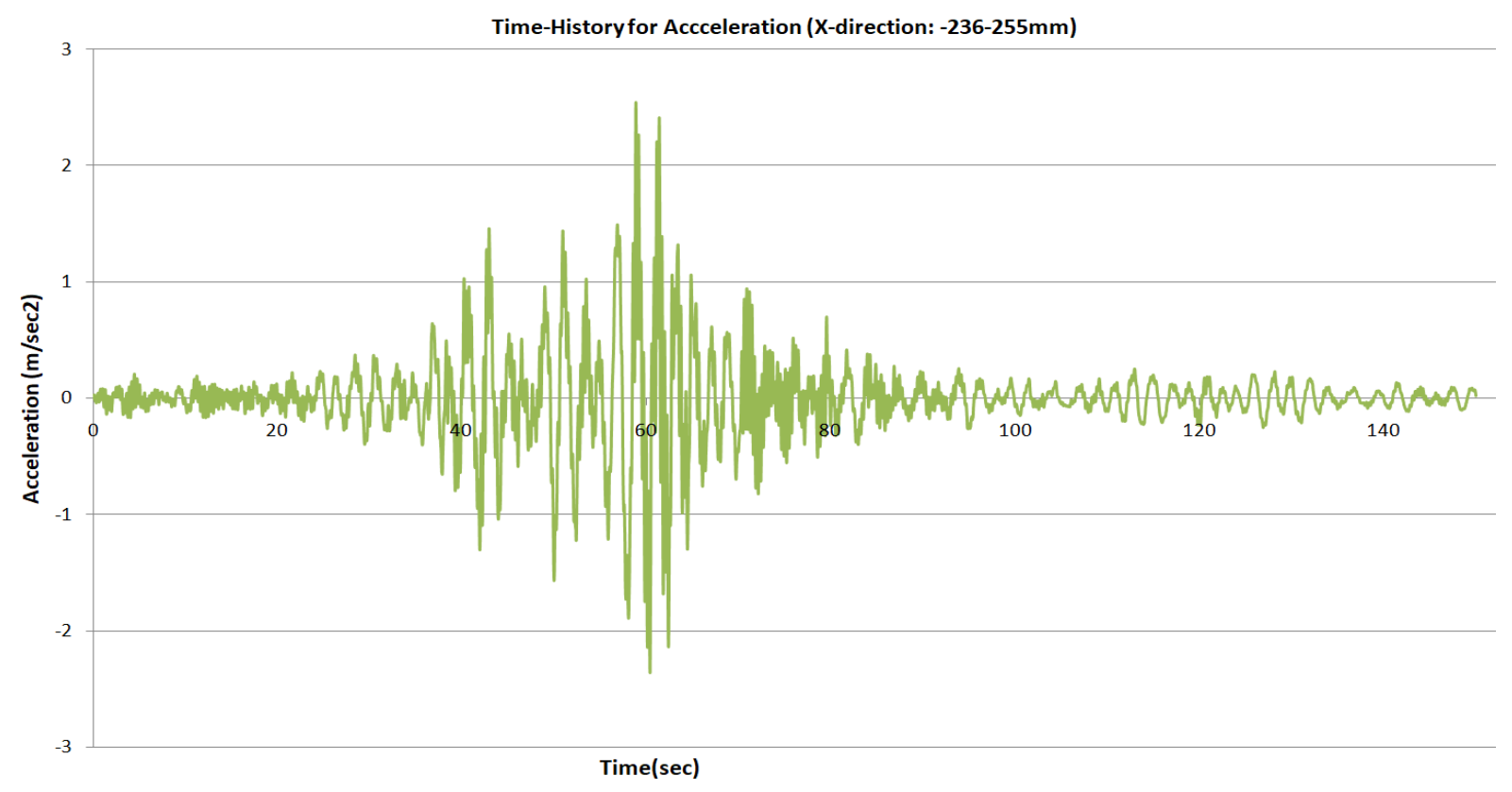

Figure 14. Acceleration response for $x$-direction (Mexico: $\mathrm{PGA}=0.1714 \mathrm{~g}$ )

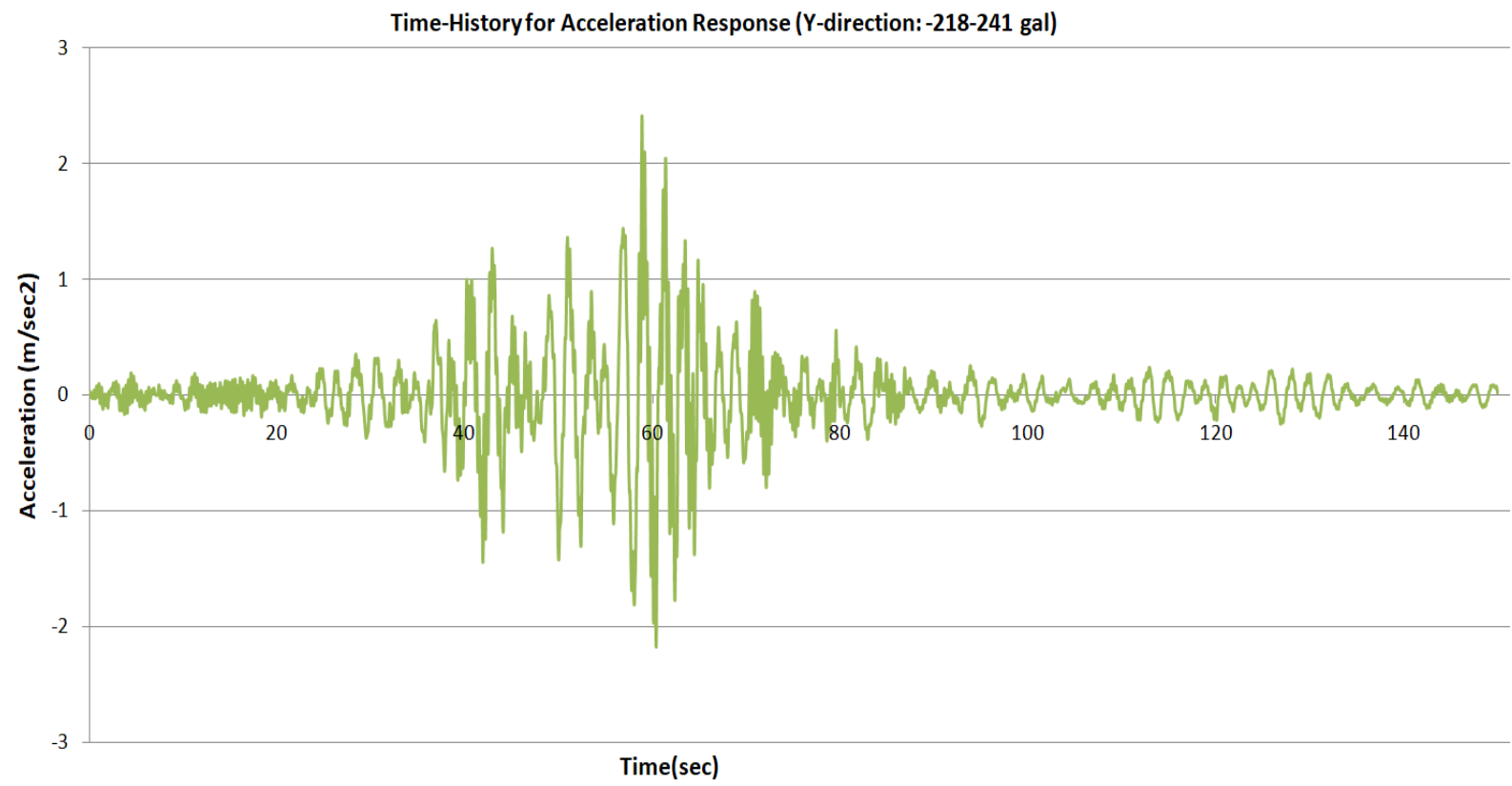

Figure 15. Acceleration response for $y$-direction (Mexico: $\mathrm{PGA}=0.1714 \mathrm{~g}$ )

\subsection{Pushover Analysis of Five-Story Buildings}

The pushover analysis conducted a seismic performance evaluation on a five-story residential building. Figure 16 shows the material nonlinear model of the column. The results were compared by applying the FEMA model and the EURO Code model in Figures 17 to 20. The $x$-direction is vulnerable to earthquake movement in the structural plan of the whole structure. Figures 17 and 18 are the performance spectrum curves for the $x$-direction by the FEMA model. Figures 19 and 20 are performance spectrum curves by the EURO Code model. 


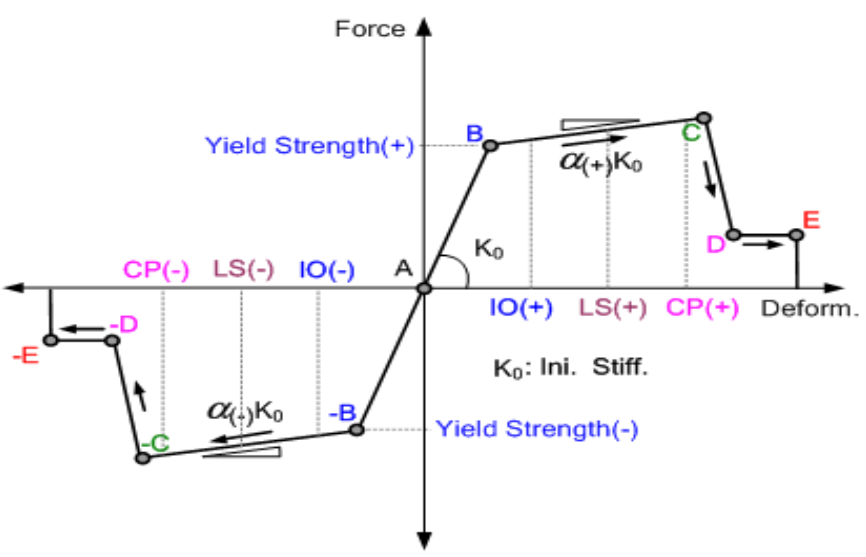

(a) plastic hinge model

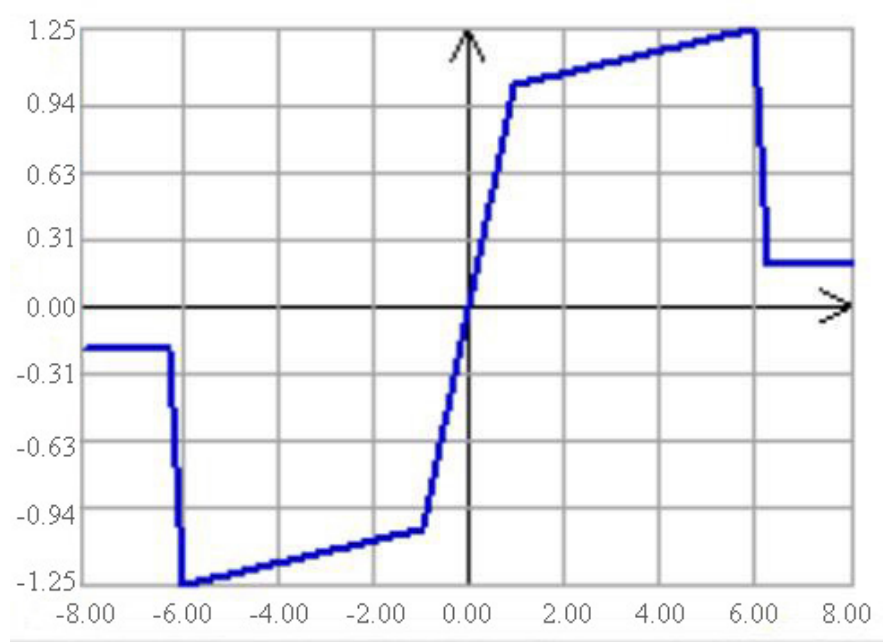

(b) FEMA

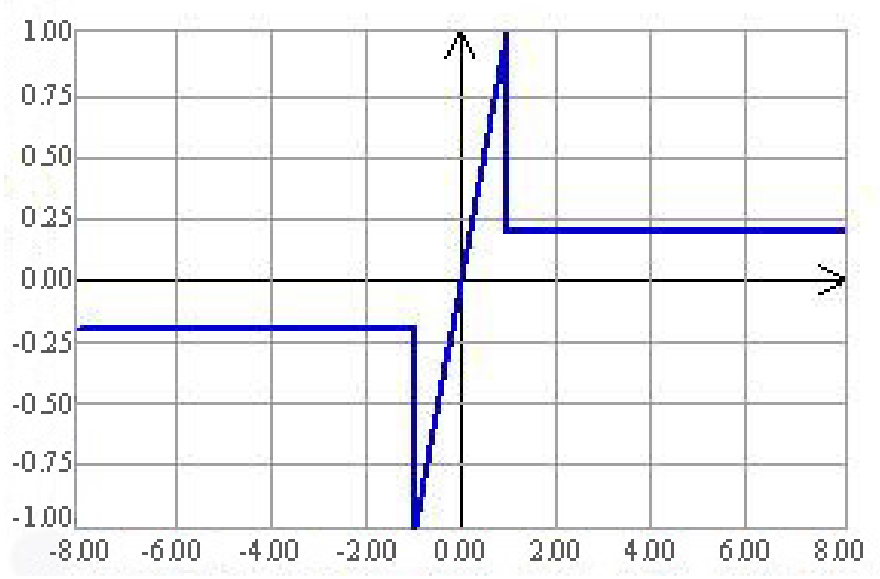

(c) EURO Code

Figure 16. Plastic properties of columns for pushover analysis (FEMA) 


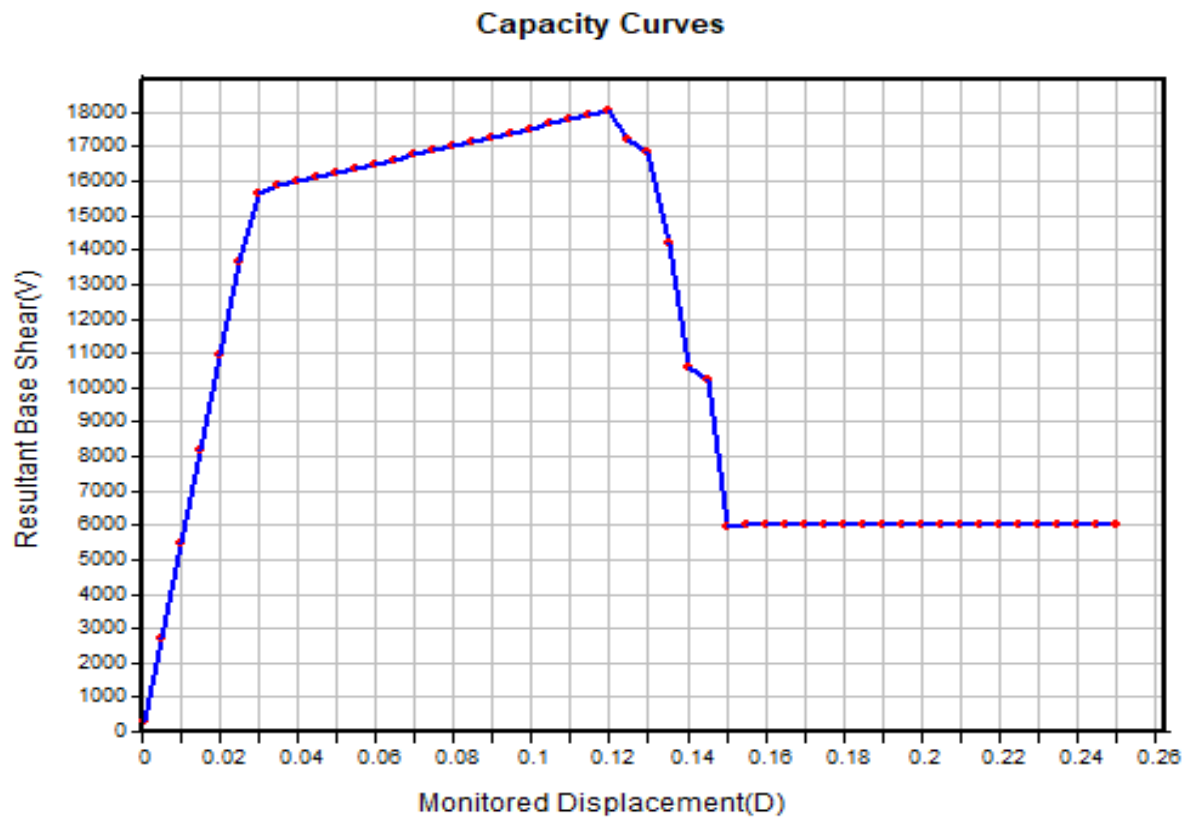

Figure 17. Base shear-displacement curve for $x$-direction (FEMA)

\section{Capacity Spectrum vs. Demand Spectrum}

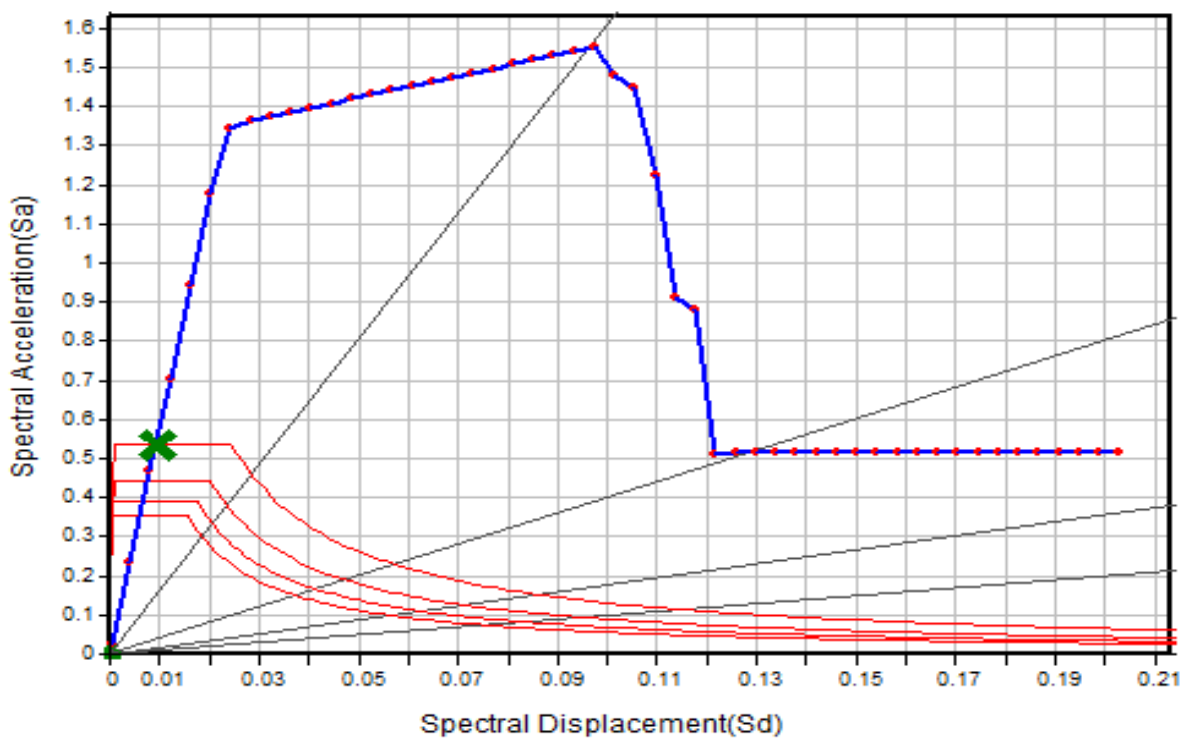

Figure 18. Acceleration and capacity spectrum for $x$-direction (FEMA) 


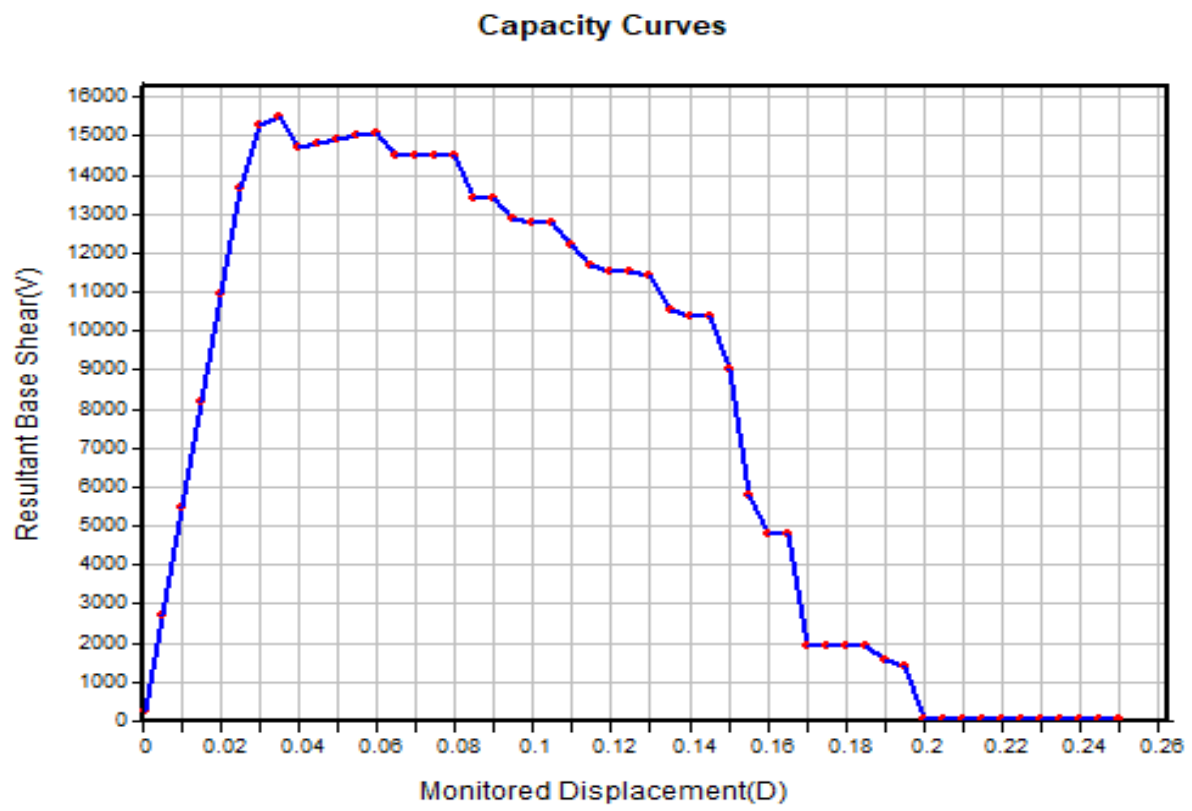

Figure 19. Base shear-displacement curve for $x$-direction (EURO Code)

Capacity Spectrum vs. Demand Spectrum

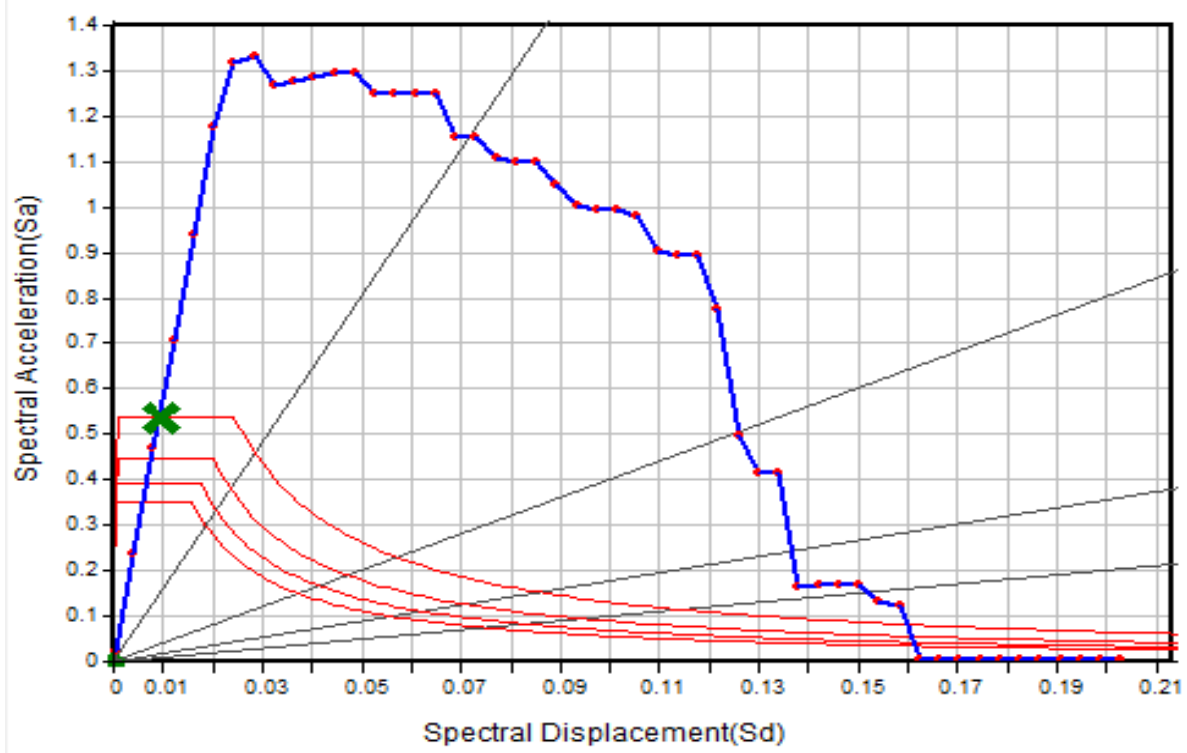

Figure 20. Acceleration and capacity spectrum for $x$-direction (EURO Code)

In the results of the pushover analysis, the shape of the curve is similar to the plastic hinge state assumed in Figure 16. Figures 17 and 18 apply the FEMA plastic hinge condition, and the base shear force is $15650 \mathrm{kN}$. Figures 19 and 20 are the analysis results applying the yield condition of the EURO Code, and the base shear force is $15498 \mathrm{kN}$. For the El Centro earthquake (maximum ground acceleration $=0.214 \mathrm{~g}$ ) and the Mexico earthquake (maximum ground acceleration $=0.1714 \mathrm{~g}$ ), the piloti building has structurally safety because the maximum deformation is less than $12 \mathrm{~mm}$. When the earthquake occurs, the structural system on the first floor is structurally weak. Figures 21 and 22 show the results of the pushover analysis by applying FEMA hinged conditions in the $y$-direction, Figures 23 and 24 show the results of the pushover analysis using the EURO Code. The column breakdown occurred at the base shear force of $13032 \mathrm{kN}$, and the column yield occurred at the base shear force of $13016 \mathrm{kN}$ when the EURO Code yield condition was applied. 


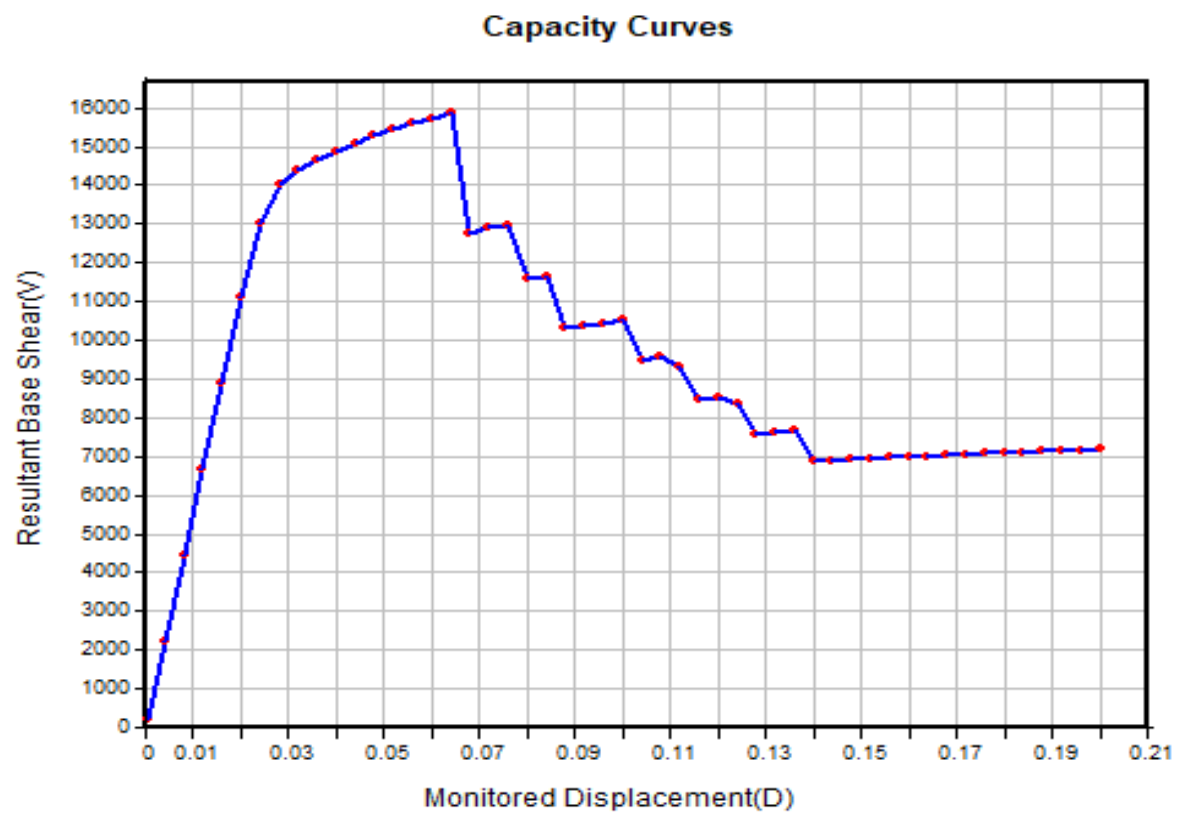

Figure 21. Base shear-displacement curve for $y$-direction (FEMA)

\section{Capacity Spectrum vs. Demand Spectrum}

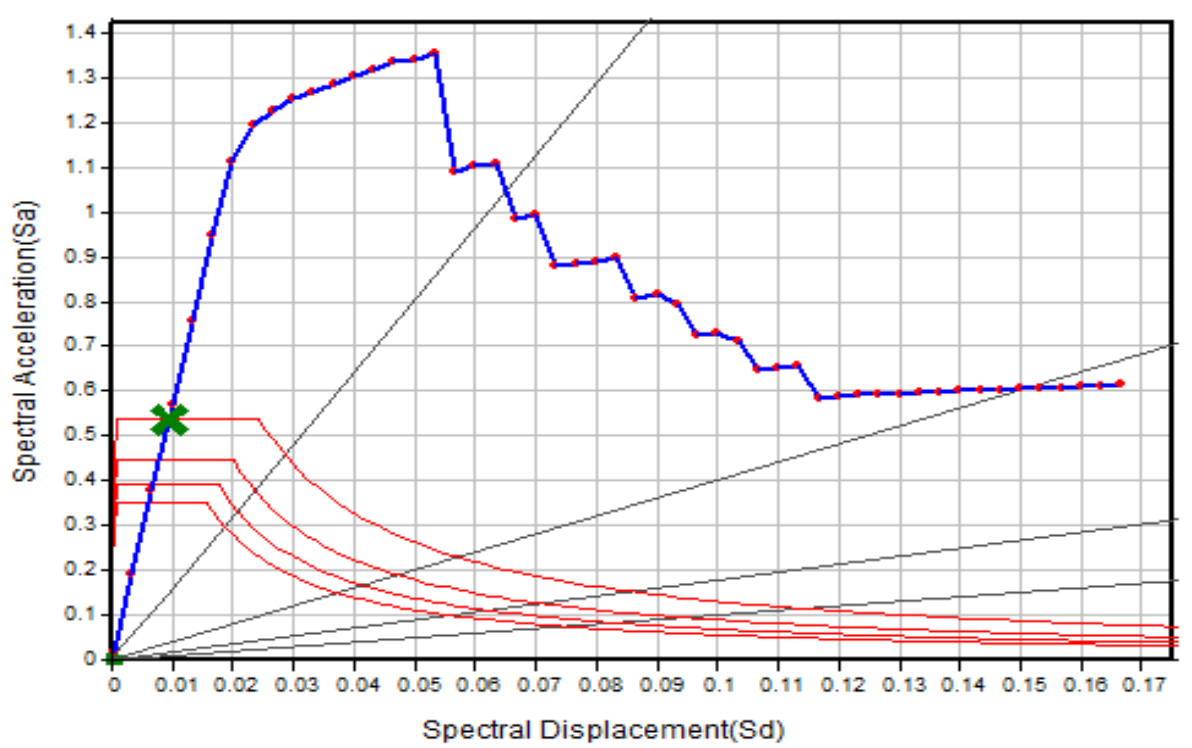

Figure 22. Acceleration and capacity spectrum for $y$-direction (FEMA) 


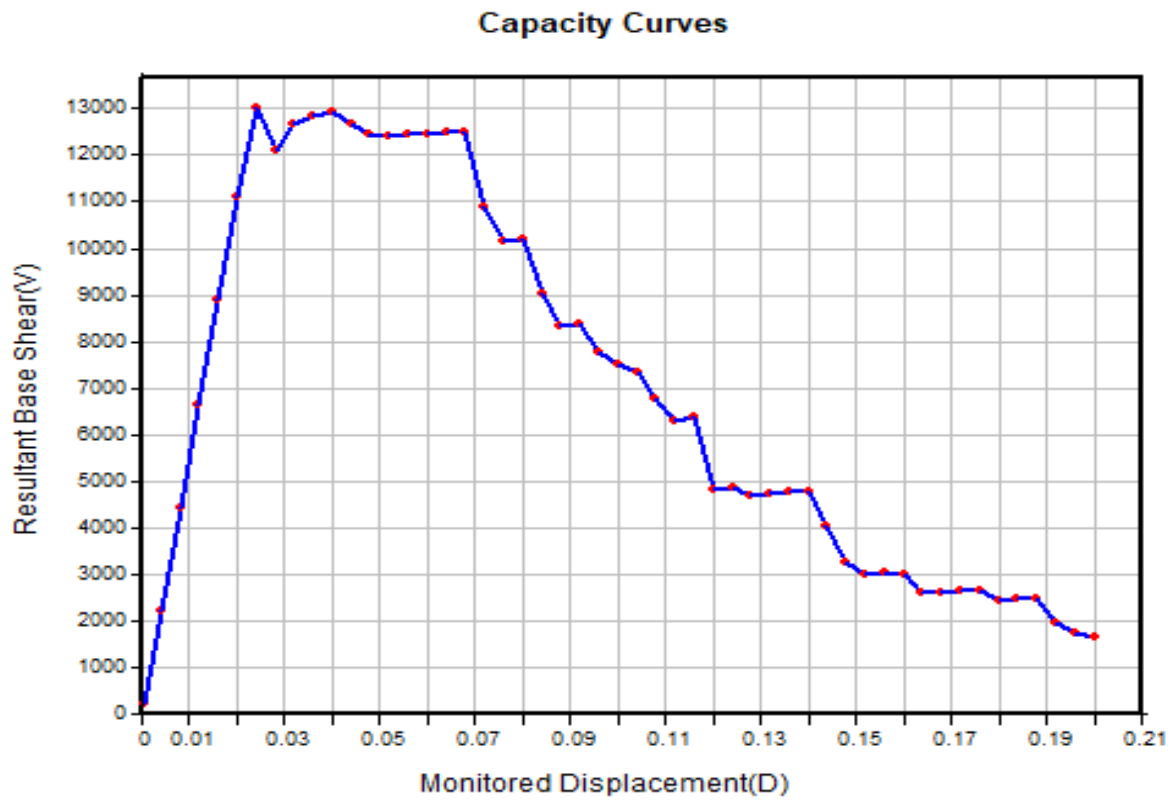

Figure 23. Base shear-displacement curve for $y$-direction (EURO Code)

Capacity Spectrum vs. Demand Spectrum

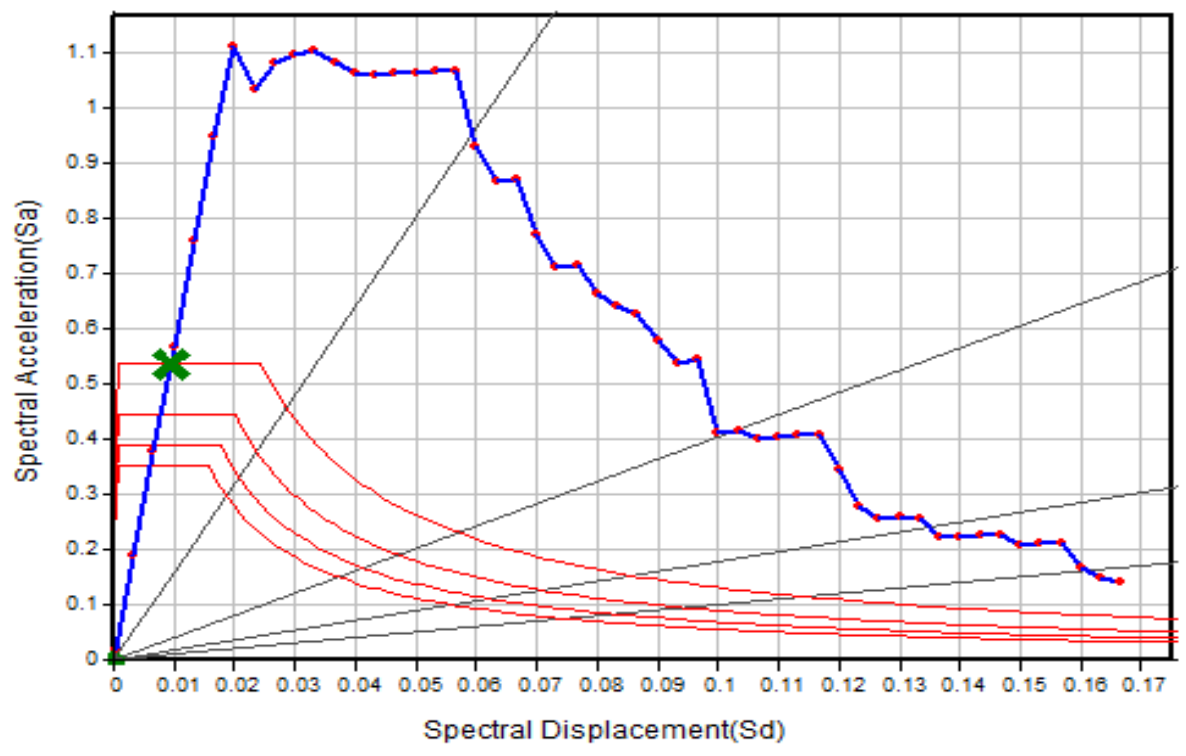

Figure 24. Acceleration and capacity spectrum for $y$-direction (EURO Code)

\section{Earthquake Response and Pushover Analysis of Ten-story Buildings}

\subsection{Earthquake Response Analysis of Ten-Story Buildings}

This study is an earthquake analysis of a ten-story piloti building with elevator core walls at the center of the building. The model has a piloti building that is open to the beam-column system on the first floor. The thickness of the inner wall is $150 \mathrm{~mm}$, and the thickness of the outer wall is $200 \mathrm{~mm}$. Figure 25 shows the analysis model and the geometry of the dynamic model. The primary period is 0.9898 , the second period is 0.9879 , and the third period is 0.8732 . The first period is dominated by the mass in the $x$-direction, and the second period is dominated by the mass in the $x$ - and $R z$-directions. The dynamic behavior of the El Centro earthquake was large in early times and gradually reduced. For the Mexico earthquake, there was a large dynamic response between $40 \mathrm{sec}$ and $80 \mathrm{sec}$. 


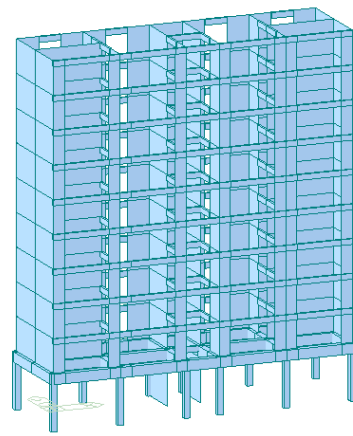

(a) model

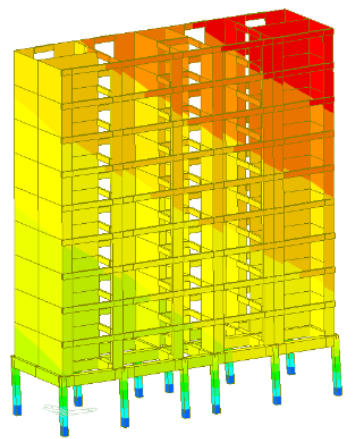

(b) mode 1

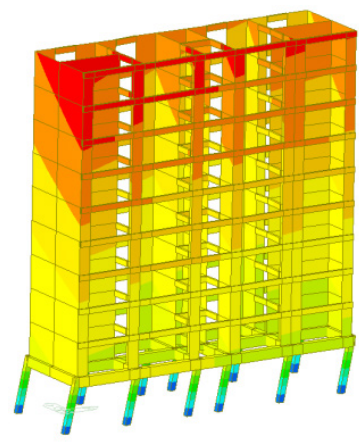

(c) mode 2

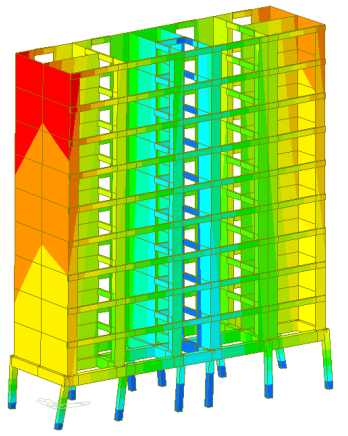

(d) mode 3

Figure 25. Model and vibration mode shape $(B \times D=8 \mathrm{~m} \times 27 \mathrm{~m}$, Box $-500 \times 500 \times 50$, SS275)

Table 3. Results for eigenvalue analysis

\begin{tabular}{|c|c|c|c|}
\hline \multirow{2}{*}{ Mode } & \multicolumn{3}{|c|}{ Eigenvalue analysis } \\
\cline { 2 - 4 } & Frequency $(\mathrm{rad} / \mathrm{sec})$ & Frequency $(\mathrm{cycle} / \mathrm{sec})$ & 0.9898 \\
\hline 1 & 6.3479 & 1.0103 & 0.9879 \\
\hline 2 & 6.3601 & 1.0122 & 0.8732 \\
\hline 3 & 7.1958 & 1.1452 & Period (sec) \\
\hline
\end{tabular}

Table 4. Nodal participation masses

\begin{tabular}{|c|c|c|c|c|c|c|}
\hline \multirow{2}{*}{ Mode } & \multicolumn{6}{|c|}{ Nodal participation masses (\%) } \\
\cline { 2 - 7 } & $\mathrm{X}$ & $\mathrm{Y}$ & $\mathrm{Z}$ & $\mathrm{Rx}$ & $\mathrm{Ry}$ & $\mathrm{Rz}$ \\
\hline 1 & 5.8459 & 91.9828 & 0.0 & 0.0 & 0.0 & 0.7219 \\
\hline 2 & 91.0907 & 6.2548 & 0.0 & 0.0 & 0.0 & 1.0924 \\
\hline 3 & 1.6161 & 0.3592 & 0.0 & 0.0 & 0.0 & 99.447 \\
\hline
\end{tabular}

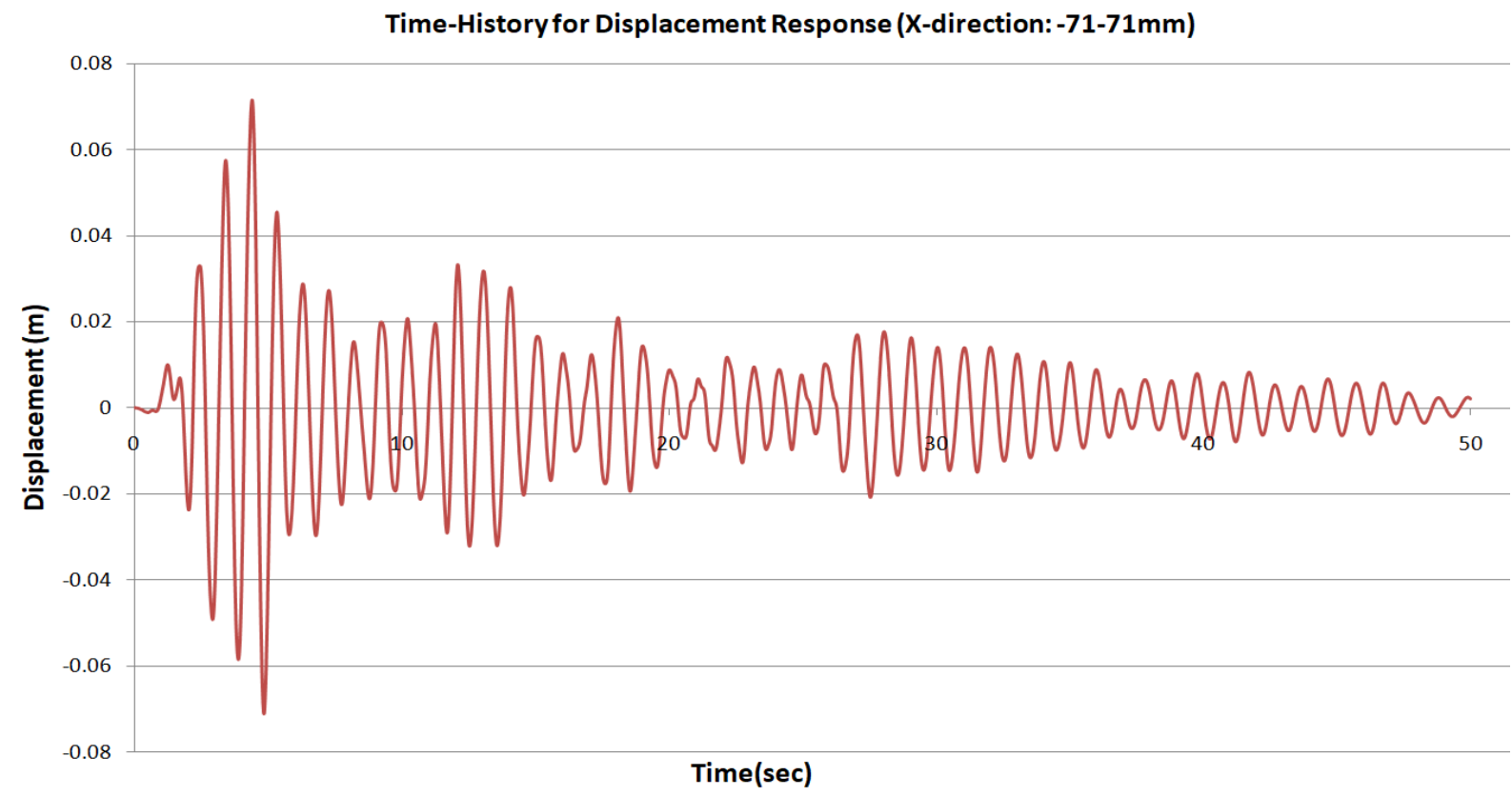

Figure 26. Displacement response for $x$-direction (El Centro: PGA $=0.3569 \times 0.6=0.214 \mathrm{~g}$ ) 


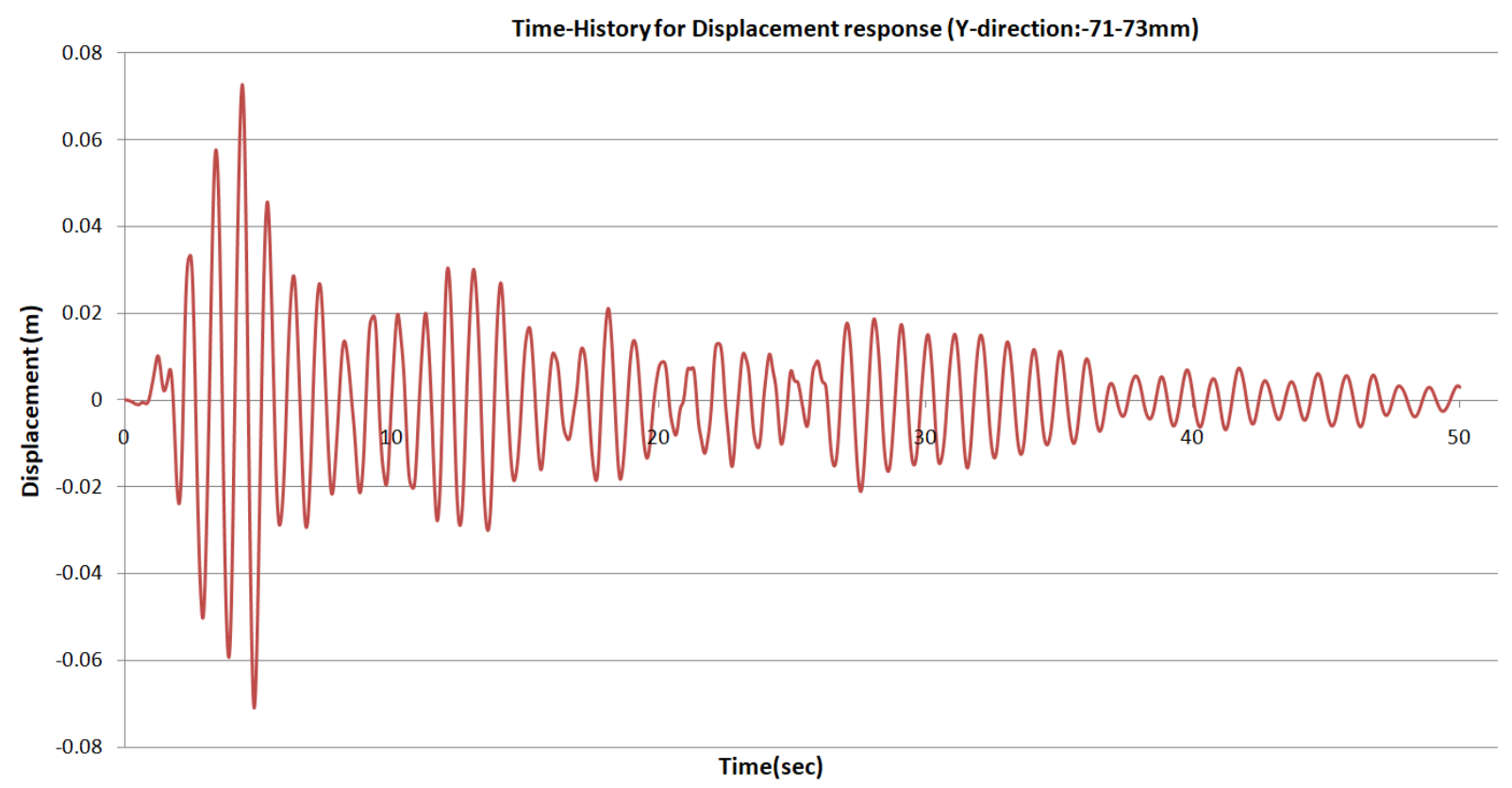

Figure 27. Displacement response for $y$-direction (El Centro: $\mathrm{PGA}=0.3569 \times 0.6=0.214 \mathrm{~g}$ )

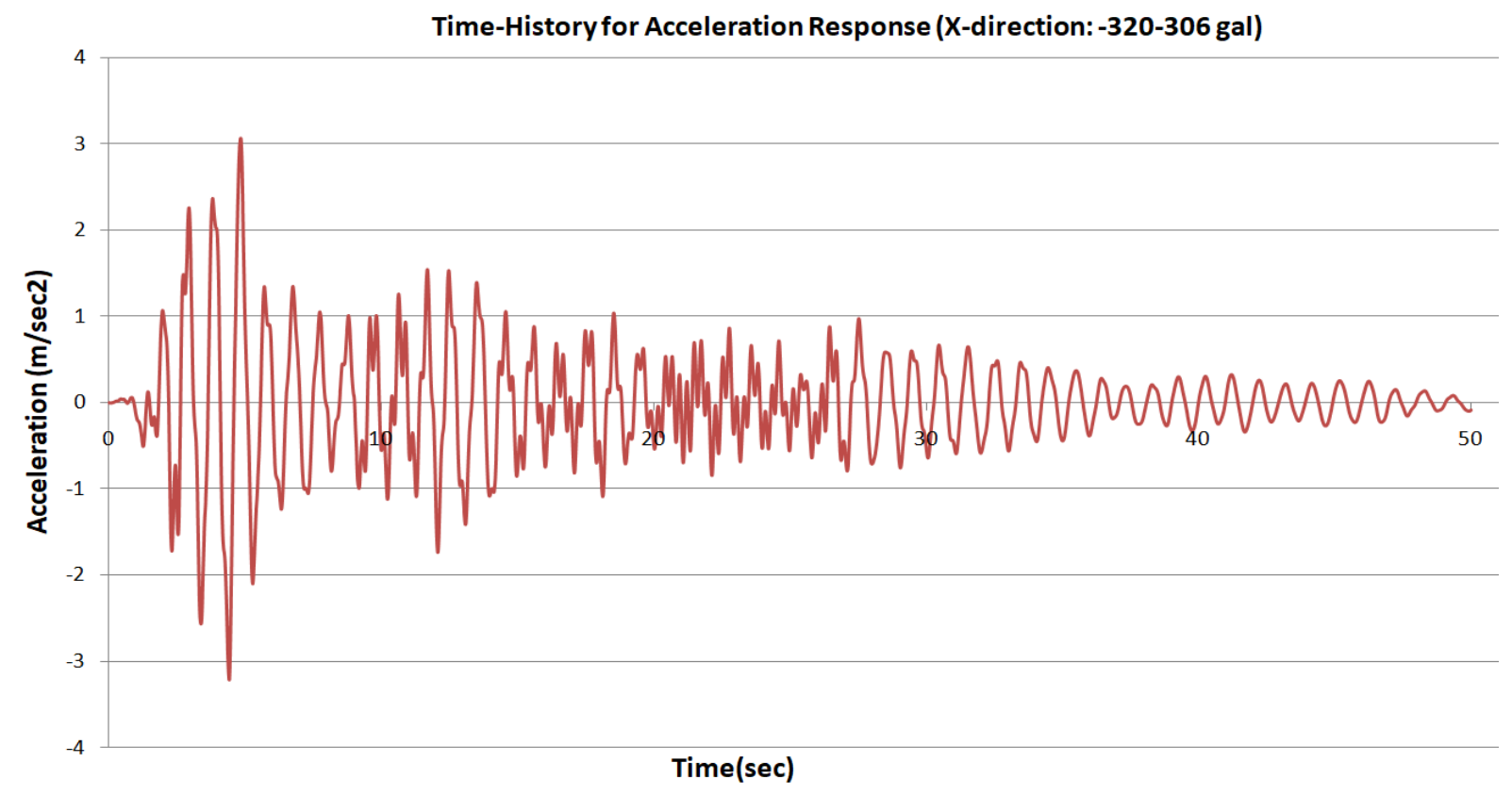

Figure 28. Acceleration response for $x$-direction (El Centro: $\mathrm{PGA}=0.3569 \times 0.6=0.214 \mathrm{~g}$ ) 


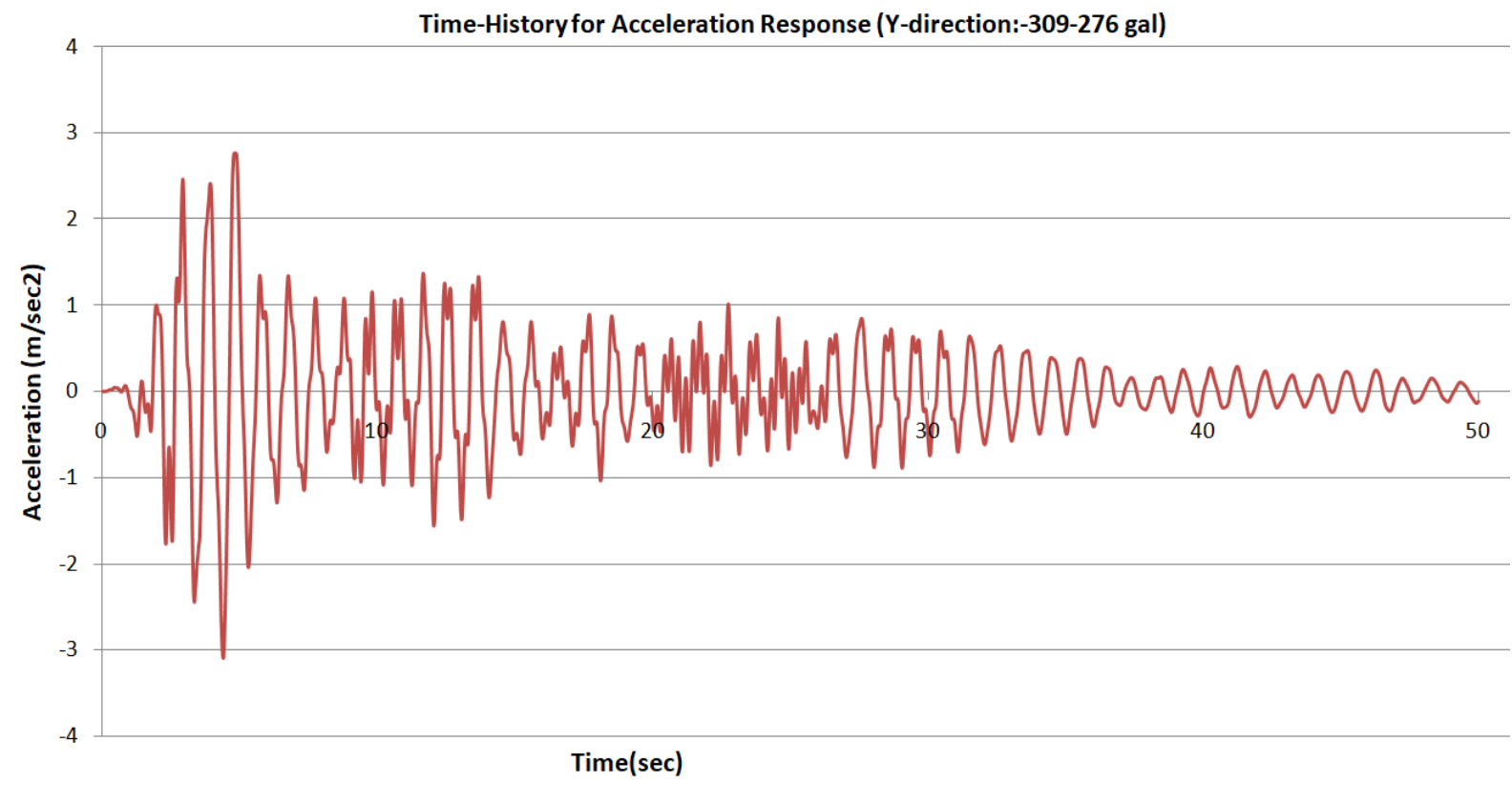

Figure 29. Acceleration response for $y$-direction (El Centro: $\mathrm{PGA}=0.3569 \times 0.6=0.214 \mathrm{~g}$ )

Time-History for Displacement Response (X-direction: -191-197mm)

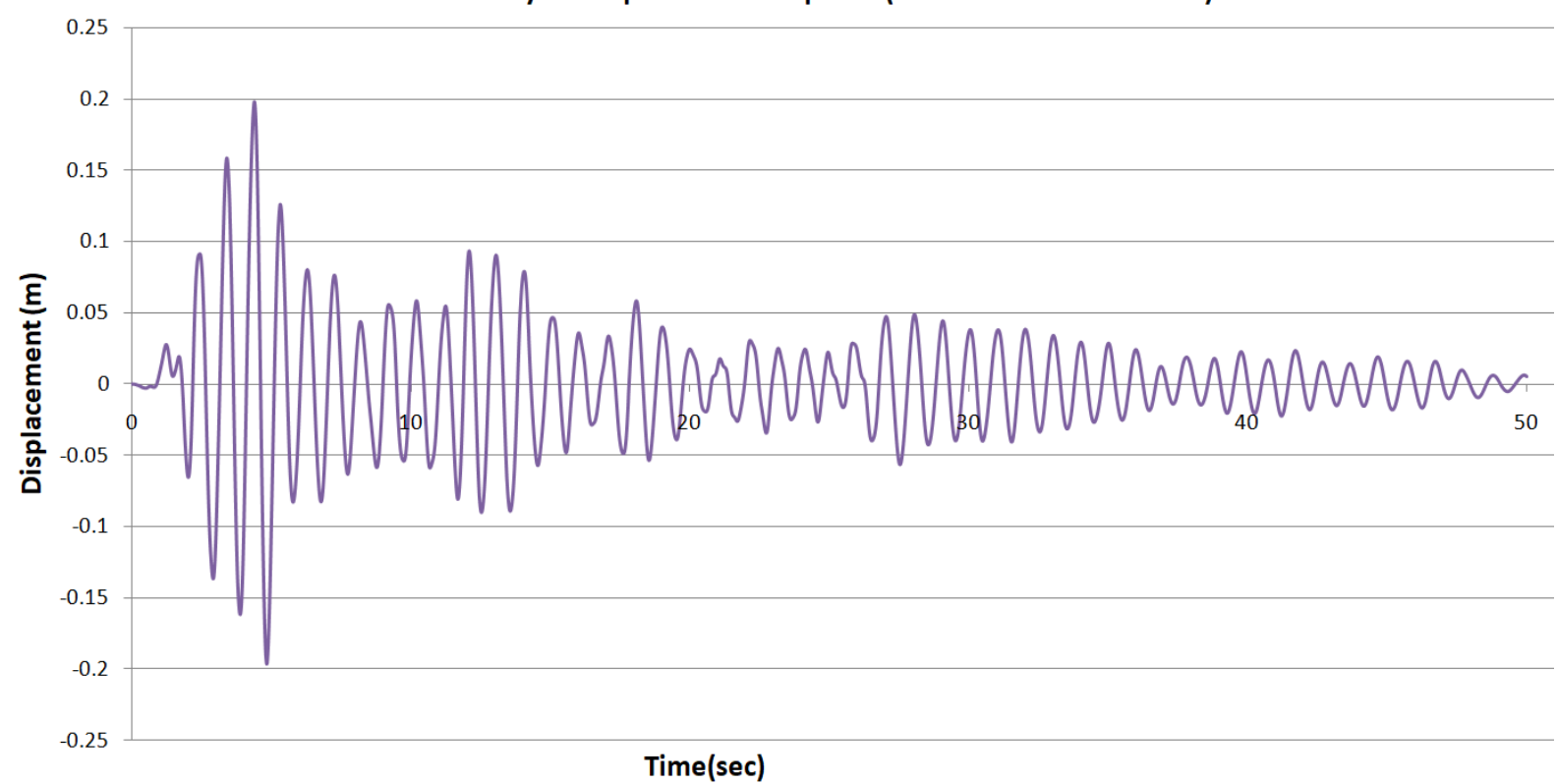

Figure 30. Displacement response for $x$-direction (El Centro: PGA $=0.3569 \mathrm{~g}$ ) 


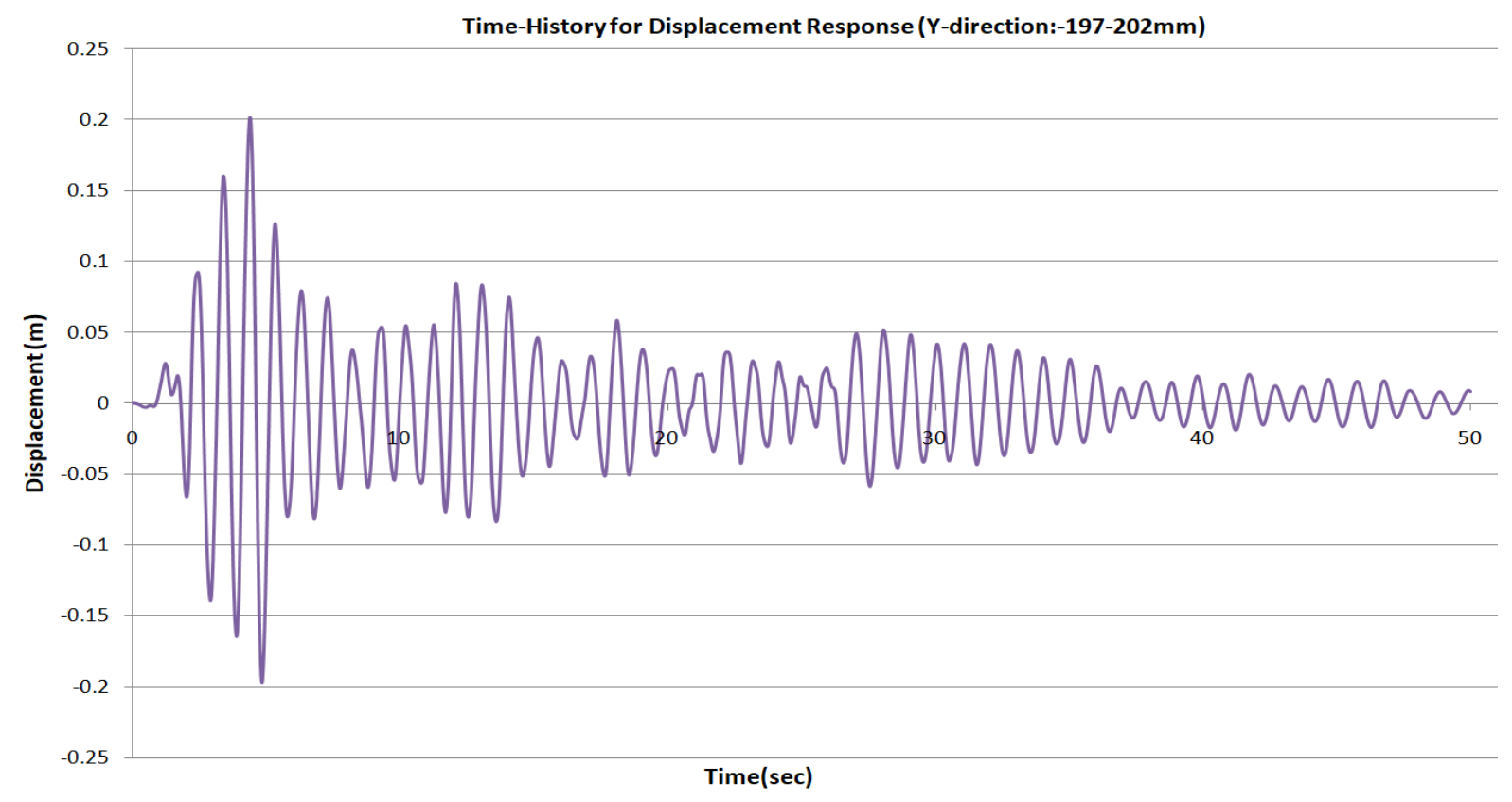

Figure 31 Displacement response for $y$-direction (El Centro: $\mathrm{PGA}=0.3569 \mathrm{~g}$ )

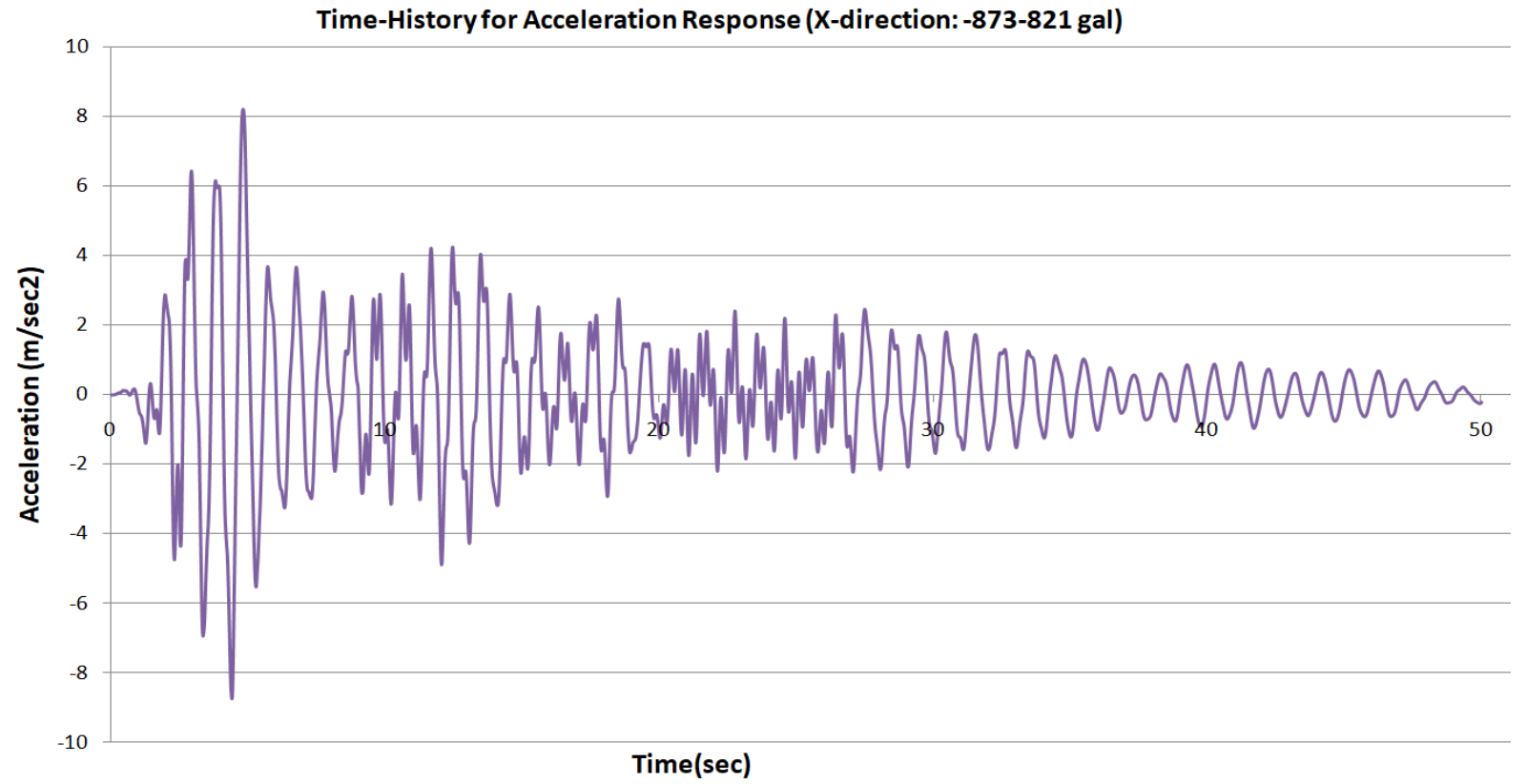

Figure 32. Acceleration response for $x$-direction (El Centro: PGA $=0.3569 \mathrm{~g}$ ) 


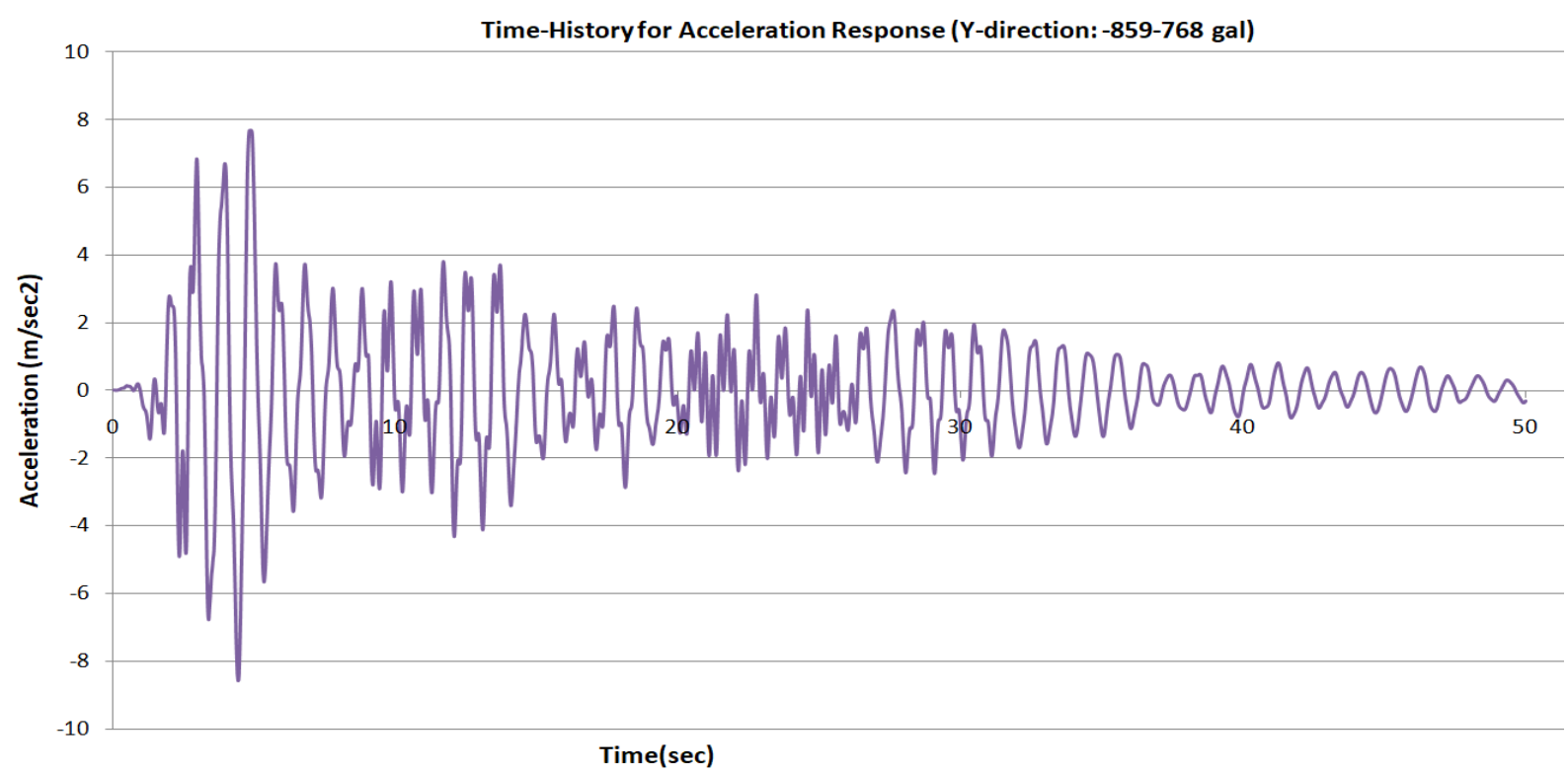

Figure 33. Acceleration response for $\mathrm{y}$-direction (El Centro: $\mathrm{PGA}=0.3569 \mathrm{~g}$ )

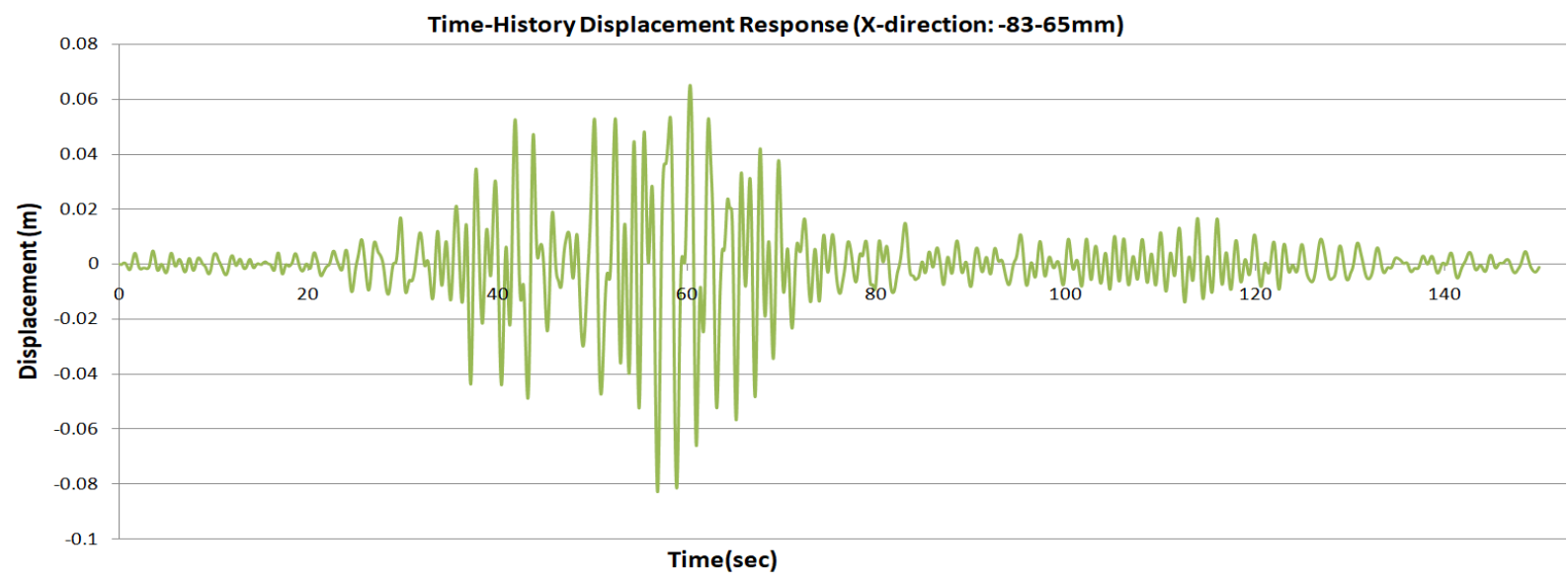

Figure 34. Displacement response for $\mathrm{x}$-direction (Mexico: $\mathrm{PGA}=0.1714 \mathrm{~g}$ )

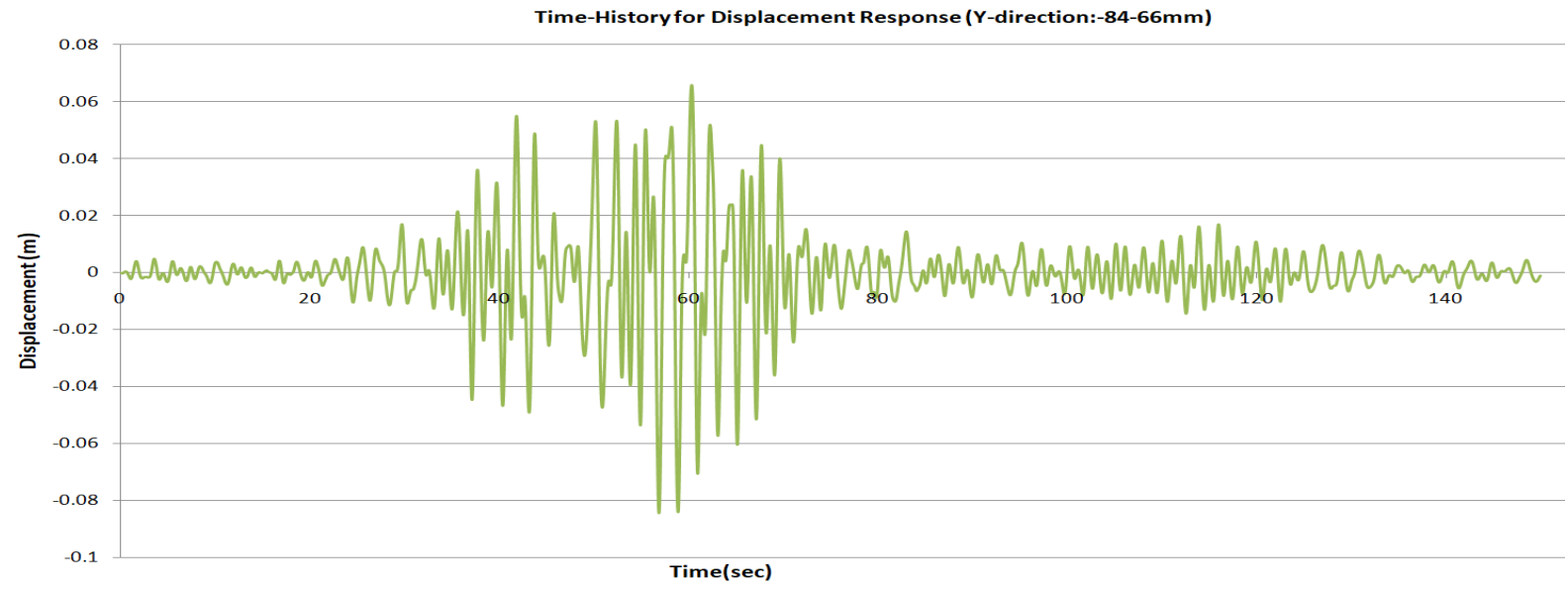

Figure 35. Displacement response for $\mathrm{y}$-direction (Mexico: $\mathrm{PGA}=0.1714 \mathrm{~g}$ ) 


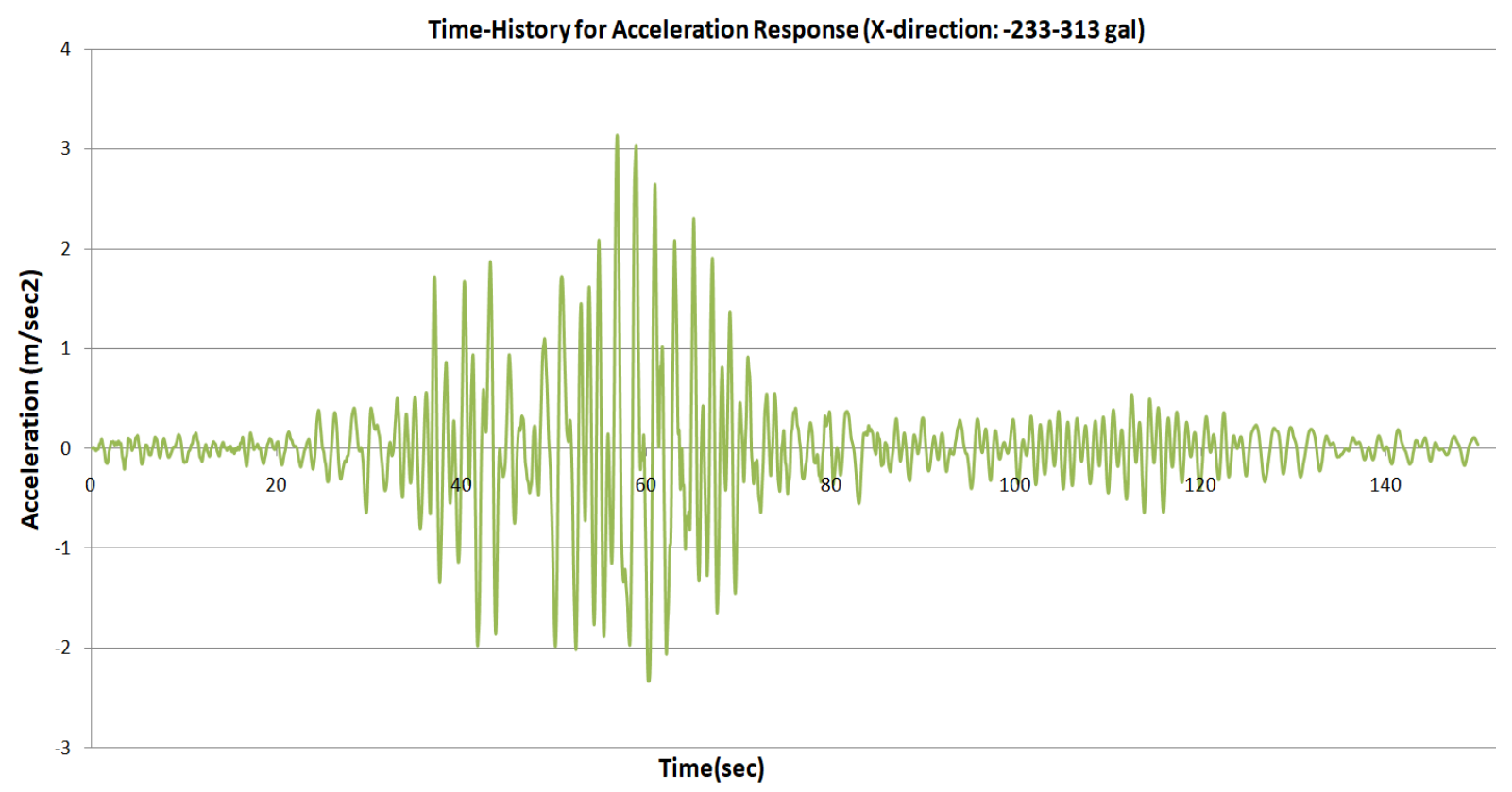

Figure 36. Acceleration response for $x$-direction (Mexico: $\mathrm{PGA}=0.1714 \mathrm{~g}$ )

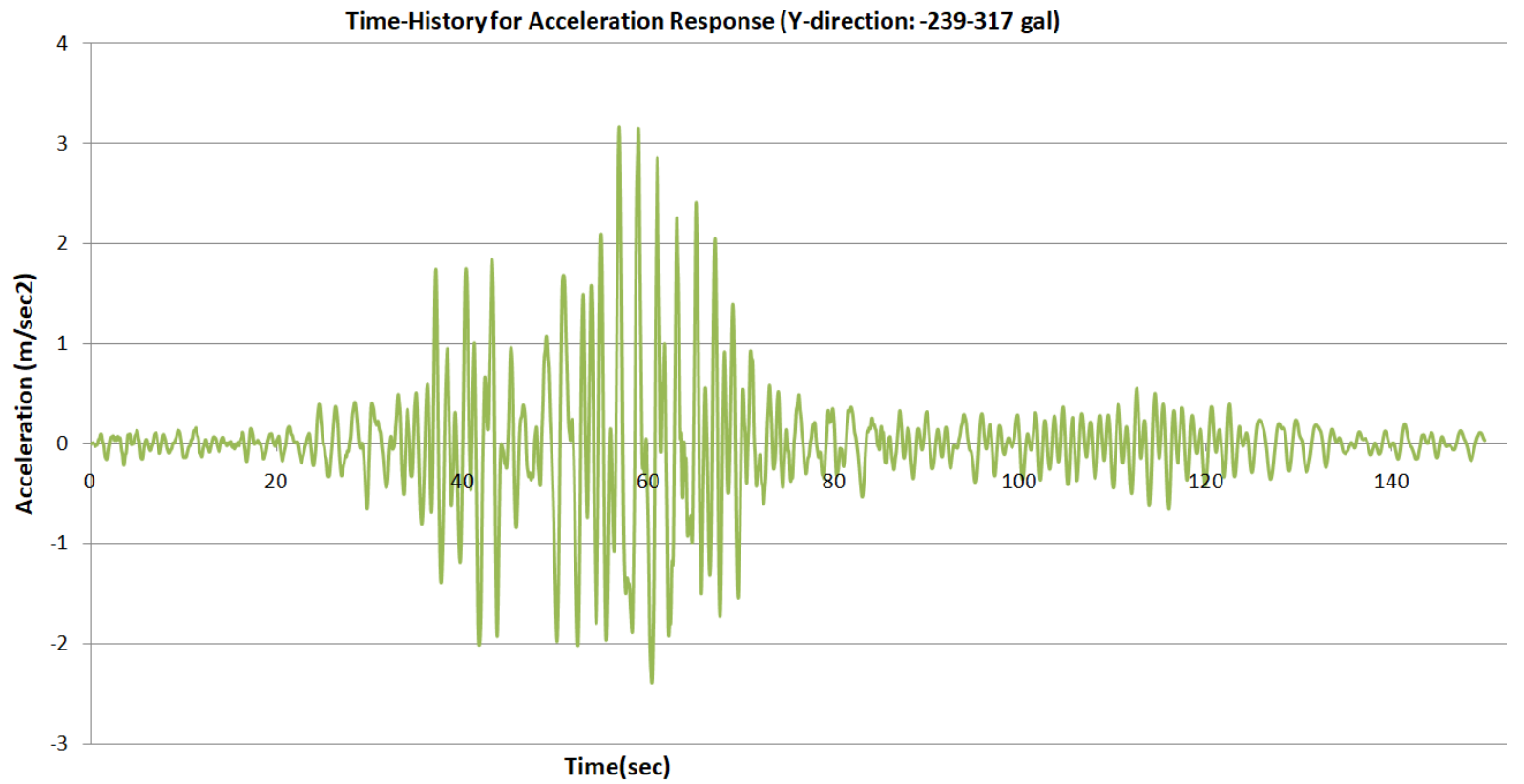

Figure 37. Acceleration response for $y$-direction (Mexico: $\mathrm{PGA}=0.1714 \mathrm{~g}$ )

\subsection{Pushover Analysis of Ten-story Buildings}

This study is performed by pushover analysis to identify the seismic performance evaluation of a ten-story piloti residential building. The first floor is open to the SRC beam-column system and the upper floor is a reinforced concrete wall structure. The elevator hall is in the center of the building, and the elevator hall is equipped with a shear wall. Figure 38 is the base shear-displacement curve in the $x$-direction using the FEMA model. Figure 39 is the acceleration and capacity spectrum curve using the FEMA model. Figures 40 and 41 are performance curves as per the EURO Code. Figures 42 and 43 are the analysis results for the FEMA hinge condition. Figures 44 and 45 are the interpretation results for the EURO Code hinge condition. The results of the FEMA and the EURO Code were similar. 


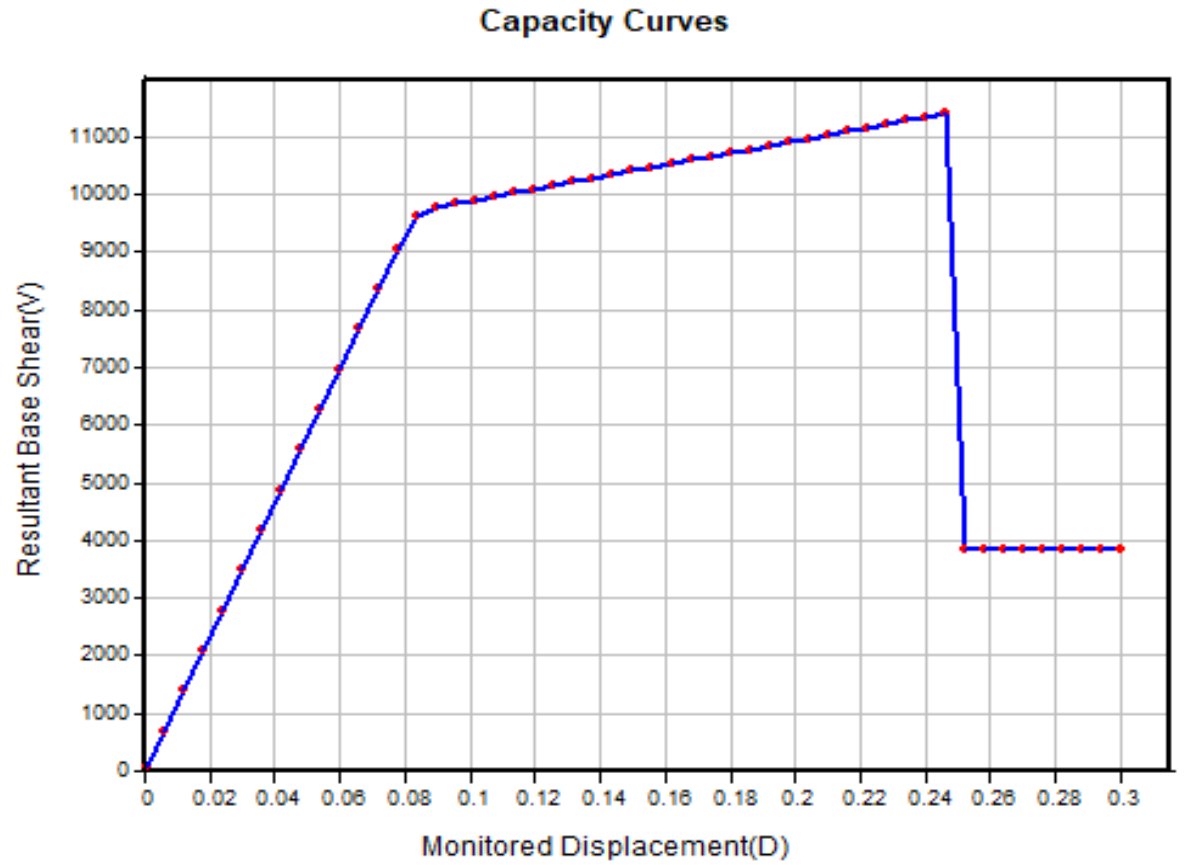

Figure 38. Base shear-displacement curve for $x$-direction (FEMA)

\section{Capacity Spectrum vs. Demand Spectrum}

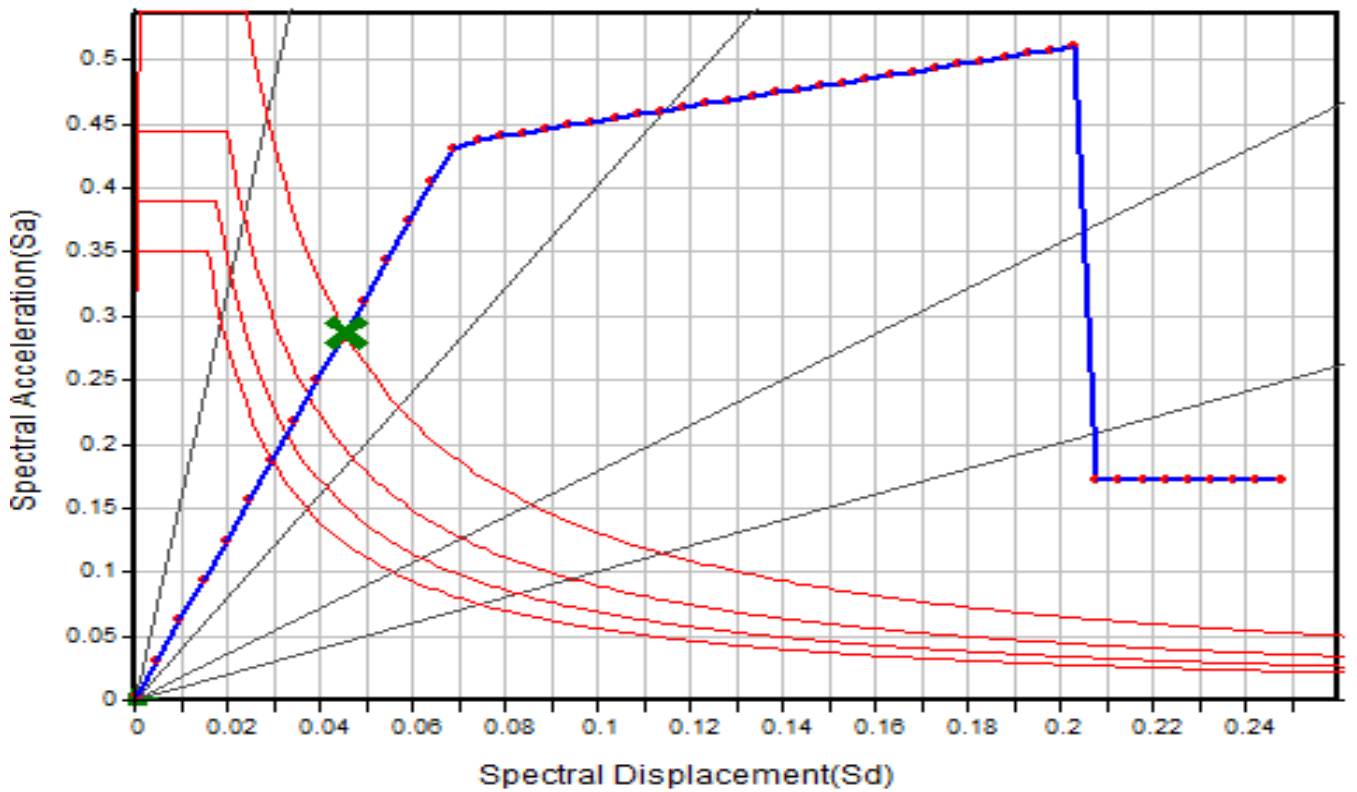

Figure 39. Acceleration and capacity spectrum for $x$-direction (FEMA) 


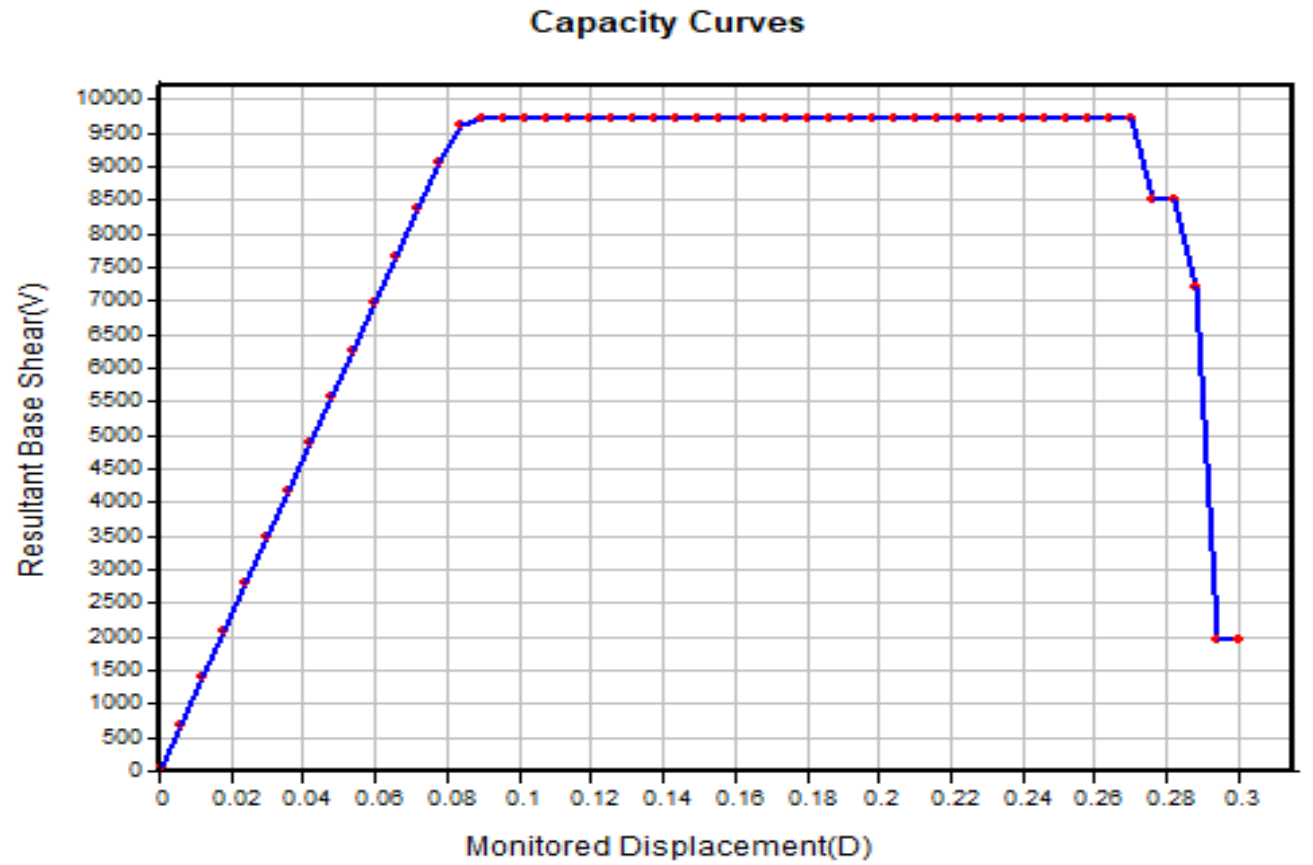

Figure 40. Base shear-displacement curve for $x$-direction (EURO Code)

\section{Capacity Spectrum vs. Demand Spectrum}

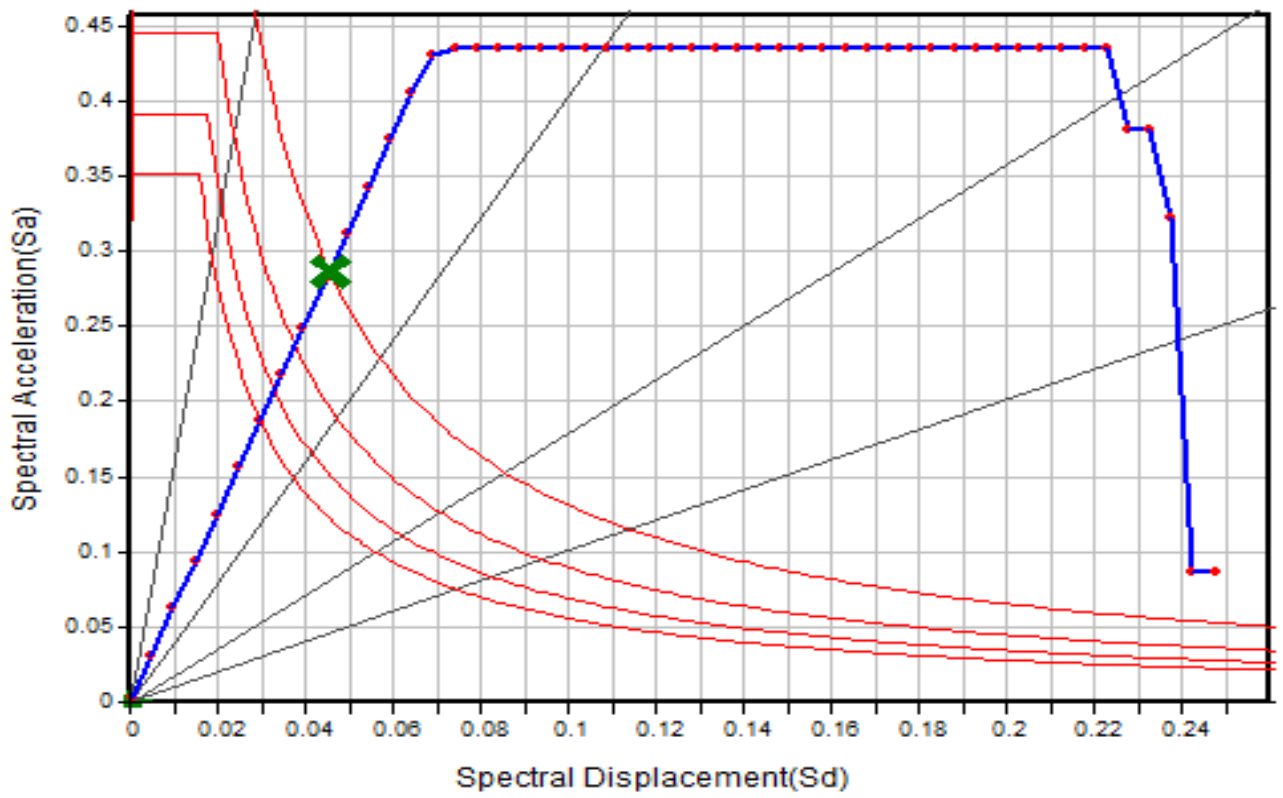

Figure 41. Acceleration and capacity spectrum for $x$-direction (EURO Code) 


\section{Capacity Curves}

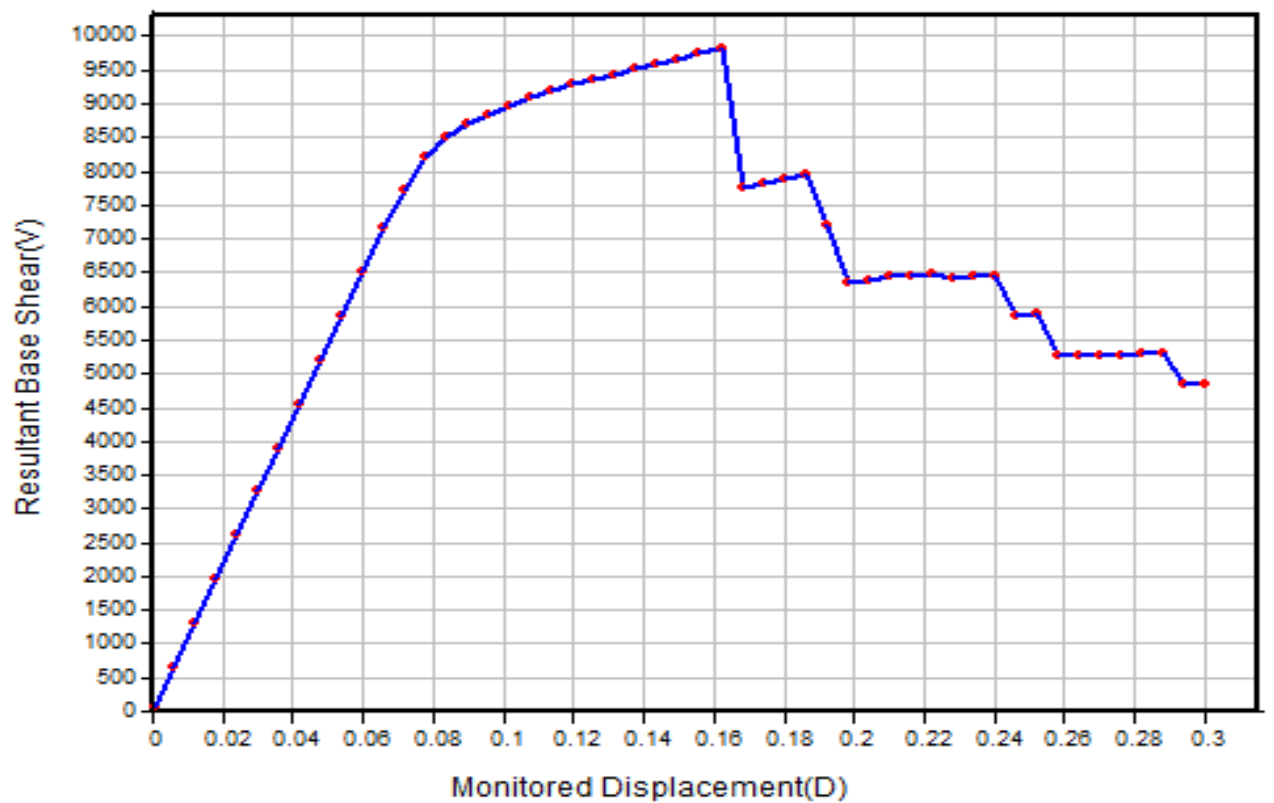

Figure 42. Base shear-displacement curve for $y$-direction (FEMA)

Capacity Spectrum vs. Demand Spectrum

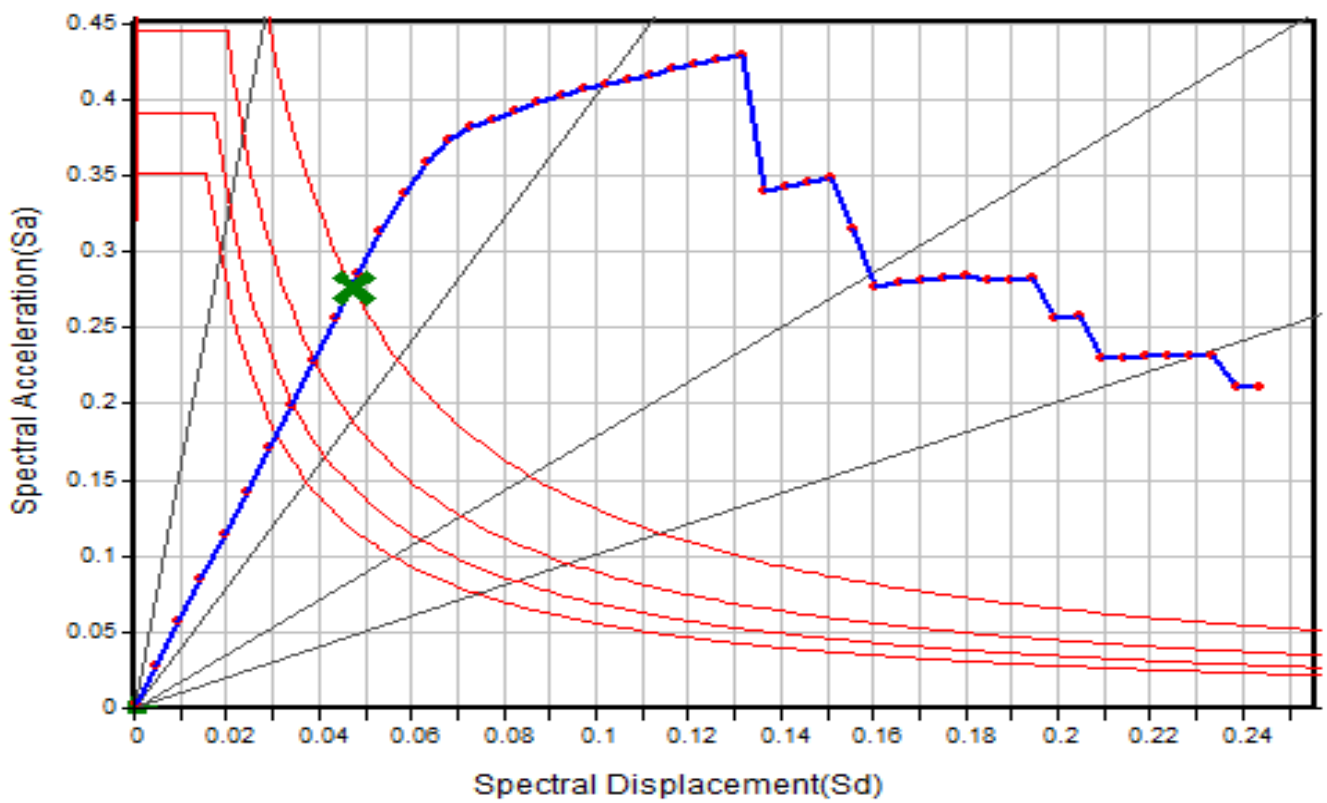

Figure 43. Acceleration and capacity spectrum for $y$-direction (FEMA) 


\section{Capacity Curves}

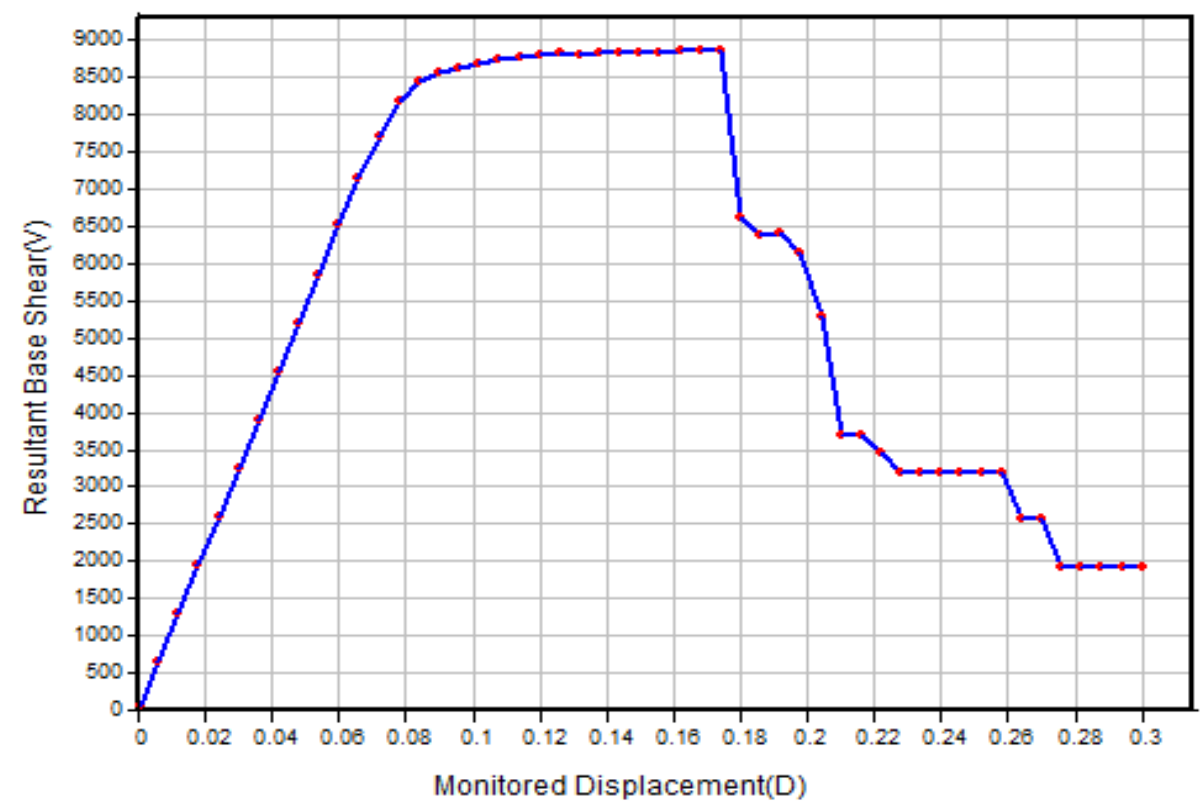

Figure 44. Base shear-displacement curve for $y$-direction (EURO Code)

\section{Capacity Spectrum vs. Demand Spectrum}

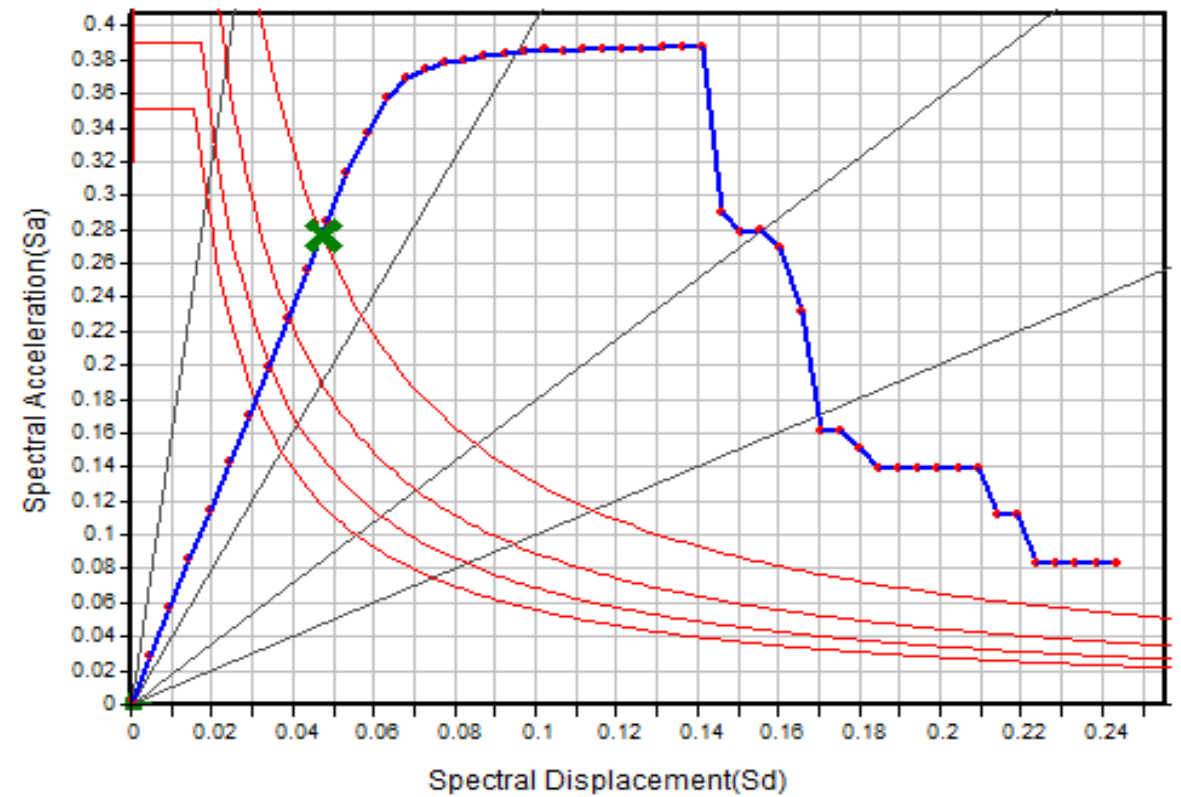

Figure 45. Acceleration and capacity spectrum for $y$-direction (EURO Code) 


\section{Conclusions}

This study evaluated earthquake response and seismic performance by conducting time history analysis and pushover analysis to evaluate the safety of piloti buildings.

1) To open the first floor, the piloti building was supported by the beam-column system. The analysis results showed patterns in which the deformation of the first-floor columns concentrated and the first-floor columns yielded and caused the collapse of the entire structure.

2) The maximum strength of the pushover analysis was similar to the plastic hinge condition of FEMA and the plastic hinge condition of the EURO Code. The curve after the yield point shows a similar shape of the originally assumed hinge condition.

3) In the time history analysis for the El Centro and Mexico earthquakes, the dynamic response to the El Centro earthquake was greater.

4) The five-story piloti building supported by SRC box columns has enough stability against the El Centro $(\mathrm{PGA}=0.3569 \mathrm{~g})$ earthquake and Mexico earthquake $(\mathrm{PGA}=0.1714 \mathrm{~g})$. It also secures a certain degree of structural stability for the ten-story piloti building.

\section{Acknowledgements}

This work was supported by the National Research Foundation of Korea(NRF) grant funded by the Korea government(MSIT) (No. 2019R1H1A210116511).

\section{REFERENCES}

[1] Moehle, J.P. (1984). "Seismic response of vertical irregular structures", Journal of Structural Engineering, Vol.110, No.9, pp.2002-2014

[2] Lu, Y., Tassio, T.P., Zhang, G.F. and Vintzileou, E. (1999). "Seismic response of reinforced concrete frame with strength and stiffness irregularities", ACI Structural Journal, Vol.96, No.12, pp.221-229

[3] Lee, K.S., Oh, J.K. (2007). "Required Strength Spectrum of Low-Rise Reinforced Concrete Shear Wall Buildings with Pilotis", Journal of The Earthquake Engineering Society of Korea, Vol.11, No.5, pp.61-69.

[4] Ko, D.W., Lee, H.S. (2009). "Non-linear Time History Analysis of Piloti-Type High-rise RC Buildings", Journal of The Earthquake Engineering Society of Korea, Vol.13, No.1, pp.35-43.

[5] Ko, H., Kim, H.S., Kang, J.W. (2010). "Evaluation of Seismic Behavior for RC Moment Resisting Frame with Masonry Infill Walls", Journal of The Engineering Society of Korea, Vol.14, No.5, pp.13-22.
[6] Park, K.G., Chung, M.J., Lee, D.W. (2018), "Earthquake Response Analysis for Seismic Isolation System of Single Layer Lattice with 300m Span", Journal of Korean Association for Spatial Structures, Vol.18, No.3, pp.105-116, 2018

[7] Choi, D.I., Kim, D.J., Park, K.G. (2019), "Dynamic Response of 100 m, 200 m, 300 m Lattice Domes with LRB Seismic Isolator", Journal of Civil Engineering and Architecture Vol. 13, pp.523-537

[8] Eurocode 8, "Seismic Design of Buildings", 2011

[9] FEMA 356, "Prestandard and Commentary of Seismic Rehabilitation of Buildings", Washington DC, 2013 